NBER WORKING PAPER SERIES

\title{
AN EQUILIBRIUM MODEL OF "GLOBAL IMBALANCES" AND LOW INTEREST RATES
}

\author{
Ricardo J. Caballero \\ Emmanuel Farhi \\ Pierre-Olivier Gourinchas \\ Working Paper 11996 \\ http://www.nber.org/papers/w11996
NATIONAL BUREAU OF ECONOMIC RESEARCH
1050 Massachusetts Avenue
Cambridge, MA 02138
January 2006

We thank Daron Acemoglu, Olivier Blanchard, Mike Dooley, Francesco Giavazzi, Maury Obstfeld, Ivan Werning, and seminar participants at MIT, MIT-Central Banks Network and SCCIE for their comments. Caballero and Gourinchas thank the NSF for financial support. First draft: September 2005. The views expressed herein are those of the author(s) and do not necessarily reflect the views of the National Bureau of Economic Research.

(O2006 by Ricardo J. Caballero, Emmanuel Farhi, and Pierre-Olivier Gourinchas. All rights reserved. Short sections of text, not to exceed two paragraphs, may be quoted without explicit permission provided that full credit, including $\odot$ notice, is given to the source. 
An Equilibrium Model of "Global Imbalances" and Low Interest Rates

Ricardo J. Caballero, Emmanuel Farhi, and Pierre-Olivier Gourinchas

NBER Working Paper No. 11996

January 2006, Revised May 2006

JEL No. E0, F3, F4, G1

\begin{abstract}
$\underline{\text { ABSTRACT }}$
Three of the most important recent facts in global macroeconomics -- the sustained rise in the US current account deficit, the stubborn decline in long run real rates, and the rise in the share of US assets in global portfolio -- appear as anomalies from the perspective of conventional wisdom and models. Instead, in this paper we provide a model that rationalizes these facts as an equilibrium outcome of two observed forces: a) potential growth differentials among different regions of the world and, b) heterogeneity in these regions' capacity to generate financial assets from real investments. In extensions of the basic model, we also generate exchange rate and FDI excess returns which are broadly consistent with the recent trends in these variables. Unlike the conventional wisdom, in the absence of a large change in (a) or (b), our model does not augur any catastrophic event. More generally, the framework is flexible enough to shed light on a range of scenarios in a global equilibrium environment.
\end{abstract}

Ricardo J. Caballero

Department of Economics

MIT

Room E52-252a

Cambridge, MA 02142-1347

and NBER

caball@mit.edu

Emmanuel Farhi

Department of Economics

MIT

Cambridge, MA 02142-1347

efarhi@mit.edu

Pierre-Olivier Gourinchas

UC Berkeley

693 Evans Hall, \#3880

Economics Department

Berkeley, CA 94720-3880

and NBER

pog@berkeley.edu 


\section{Introduction}

Three facts have dominated the discussion in global macroeconomics in recent times:

Fact 1: The US has run a persistent current account deficit since the early 1990s, which has accelerated dramatically since the late 1990s. Today, it exceeds US\$600 billions a year. The solid dark line in Figure 1(a) illustrates this path, as a ratio of World's GDP (this line also includes the deficits of the U.K. and Australia, for reasons that will be apparent below, but it is overwhelmingly dominated by the U.S. pattern). The counterpart of these deficits has been driven by the surpluses in Japan and Continental Europe throughout the period and, starting at the end of the 1990s, by the large surpluses in Asia ex-Japan, commodity producers, and the turnaround of the current account deficits in most non-European emerging market economies.

Fact 2: The long run real interest rate has been steadily declining over the last decade, despite recent efforts from central banks to raise interest rates (the "Greenspan's Conundrum"). See Figure 1(b).

Fact 3: The importance of US assets in global portfolios has increased throughout the period and now amounts to over 17 percent of the rest of the world's financial wealth, which is equivalent to 43 percent of their annual output. See Figure 1(c).

Despite extensive debates on the factors behind and sustainability of this environment, there are very few formal structures to analyze these joint phenomena. The conventional view and their recent formalizations, attempt mostly to explain (the first half of) fact 1, largely ignore fact 2, and take 3 as an exogenous anomaly. The analysis about the future then consists of telling the story that follows once this "anomaly" goes away. However, capital flows are primarily an asset market phenomenon and hence the paths of interest rates and portfolios must be made an integral part of the analysis if we are to conjecture on what got the world into the current situation and how it is likely to get out of it. ${ }^{1}$

The main purpose of this paper is to provide a framework to analyze global equilibrium and, as an important side product, shed some light on the above facts. The model is fairly standard in its ingredients and provides a simple asset-demand and (most importantly) -supply framework to characterize the impact of different shocks on global capital flows, interest rates and portfolios. We use this model to show that the patterns in Figure 1 (together with observed exchange rate and gross flows patterns) can arise naturally from observed growth and financial market shocks, which interact with heterogeneous degrees of financial market development in different regions of the world.

We divide the world into three groups: The US (and "similar" economies such as Australia and the U.K.) $(U)$; the EuroZone/Japan $(E)$; and the rest $(R)$. The latter include emerging markets, oil producing

\footnotetext{
${ }^{1}$ Recently, some of the debate in policy circles also has began to highlight the role of equilibrium in global capital markets for US current account deficits. See especially Bernanke (2005) and IMF (2005). We will revisit the "saving glut" view after we have developed our framework.
} 


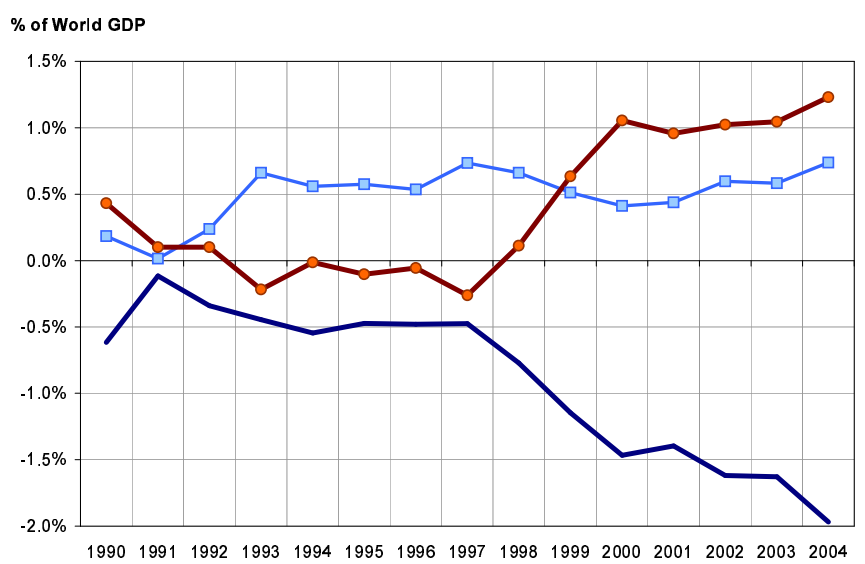

-USA, Australia, UK $\rightarrow-E U$, Japan $\rightarrow$ ROW

(a) Current Account by Region (percent of world output)

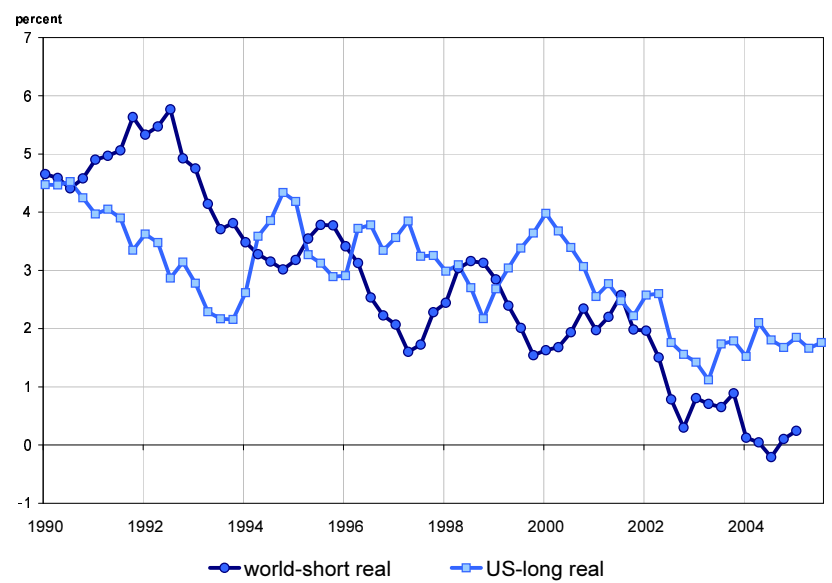

(b) World and US Real Interest Rates

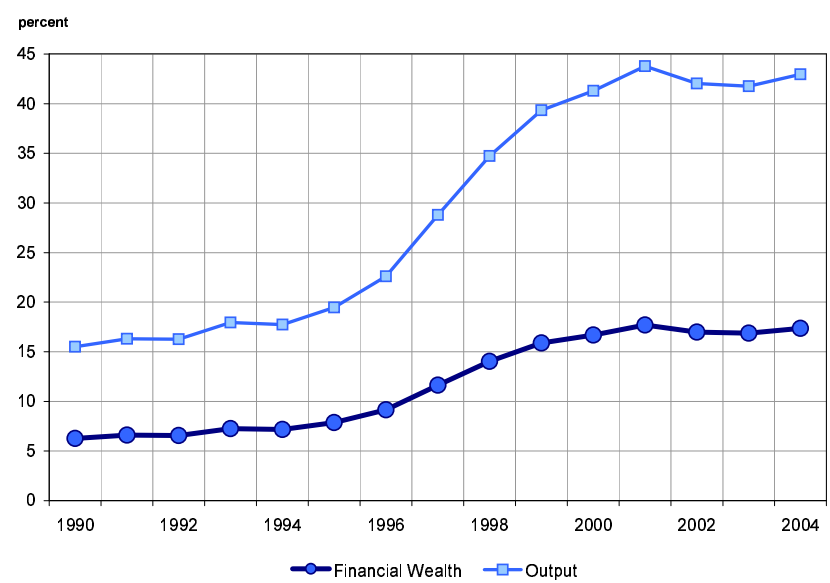

(c) Share of US Assets in Rest of the World's Output and Financial Wealth

Figure 1: Three Stylized Facts. Sources: (a) WDI and Deutsche Bank. (b) International Financial Statistics and Survey of Professional Forecasters. (c) World Development Indicators, Bureau of Economic Analysis, European Central Bank, Bank of Japan and Authors' calculations (see appendix) 
countries, and high saving newly industrialized economies, such as Hong-Kong, Singapore and Korea. Both $U$ and $E$ produce good quality financial instruments. $R$, on the other hand, has high growth potential but has episodes when it cannot generate "enough" reliable savings instruments. ${ }^{2}$

In this world, we investigate the implication of a growth slowdown in $E$ and, primarily, a collapse in asset markets in $R$. We show that both shocks point in the same direction, in terms of generating a rise in capital flows toward $U$, a decline in real interest rates, and an increase in the importance of $U$ 's assets in global portfolios. Importantly, while there are natural forces that undo some of the initial trade deficits in $U$, these are tenuous, as $U$ 's current account never needs to turn into surplus and capital flows indefinitely toward $U$.

The key feature of the model is that it focuses on the regions' ability to supply financial assets to savers. Regions $U$ and $E$ compete on asset production. Region $R$ demands financial assets. Thus, fast growth in $R$ coupled with their inability to generate local store of value instruments increases their demand for saving instruments from $U$ and $E$. More growth potential in $U$ than in $E$ means that a larger share of global saving flows to $U$.

In the basic model productive assets are (implicitly) run by local agents and there is a single good. We relax these assumptions in extensions. In the first one we allow for foreign direct investment (FDI), whose main reason is transfering "corporate governance" standards from one country to the other. In this context FDI from $U$ to $R$ improves the financial quality of assets created from investments in $R$, and in the process generate rents for $U$. Moreover, these rents allow $U$ to finance permanent trade deficits.

In the second extension we allow for heterogeneous goods and discuss (real) exchange rate determination. The exchange rate patterns generated by the expanded model in response to the shocks highlighted above are broadly consistent with those observed in the data - in particular, $U$ appreciates vis a vis both, $R$ and $E$ and anticipate a very limited and slow depreciation of $U$ 's exchange rate in the absence of further shocks.

There are several recent articles related to the $U-E$ analysis in our paper. For instance, Blanchard, Giavazzi and Sa (2005) analyzes US external imbalances from the point of view of portfolio balance theory à la Kouri (1982). Their approach takes world interest rates as given and focuses on the dual role of the exchange rate in allocating portfolios between imperfectly substitutable domestic and foreign assets and relative demand through the terms of trade. In their model, the large recent US current account imbalances result from exogenous increases in U.S. demand for foreign goods and in foreign demand for U.S. assets. Their model predicts a substantial future depreciation of the US dollar since the exchange rate is the only

\footnotetext{
${ }^{2}$ See Caballero and Krishnamurthy (2006) for a model of bubbles in emerging markets as a result of their inability to generate reliable financial assets. When local bubbles crash, countries need to seek store of value abroad. This pattern also could arise from a fundamental shock due to a change in public perception of the soundness of the financial system and local conglomerates, degree of "cronysm," and so on.
} 
equilibrating variable and current account deficits must be reversed. Obstfeld and Rogoff (2004) and (2005) consider an adjustment process through the global reallocation of demand for traded versus non traded and domestic versus foreign goods. Their analysis takes as given that a current account reversal needs to occur in the US, as well as the levels of relative supply of traded and non-traded goods in each country. Because the current account deficits represents a large share of traded output, they too, predict a large real depreciation of the dollar. These papers differ from ours in terms of the shocks leading to the current "imbalances", our emphasis on equilibrium in global financial markets and, most importantly, on the connection between this equilibrium and the countries' ability to produce sound financial assets.

For the $U-E$ part, the closest paper in terms of themes and some of the implications is Caballero, Farhi and Hammour (forthcoming 2006), who present several models of speculative investments booms in $U$ and low global interest rates. One of the mechanisms they discuss is triggered by a slowdown in investment opportunities in $E$. However the emphasis in that paper is on the investment side of the problem and ignores the role of $R$ and asset supply, which are central to our analysis in this paper. Kraay and Ventura (forthcoming 2006) analyze an environment similar to that in Caballero et al.. Their emphasis is on the allocation of excess global savings to a US bubble but it does not connect capital flows to growth and domestic financial markets fundamentals as we do here.

For the $U-R$ part, Dooley, Folkerts-Landau and Garber (2003) and Dooley and Garber (forthcoming 2006) have argued that the current pattern of US external imbalances does not represent a threat to the global macroeconomic environment. Their "Bretton Woods II" analysis states that the structure of capital flows is optimal from the point of view of developing countries trying to maintain a competitive exchange rate, to develop a productive traded good sector, or to absorb large amounts of rural workers in the industrial sector. Unlike theirs, our analysis emphasizes the role of private sector capital flows and argues that the exchange rate is mostly a sideshow. ${ }^{3}$

Section 2 is the core of the paper and presents the main model and mechanisms. Section 3 introduces a foreign direct investment margin, while Section 4 analyzes exchange rate determination. Section 5 concludes and is followed by several appendices.

\footnotetext{
${ }^{3}$ We do not deny the existence of large reserves accumulation by China and others. Nonetheless, we make three observations. First, most of these reserves are indirectly held by their local private sectors through (quasi-collateralized) low-return sterilization bonds in a context with only limited capital account openness. Second, US gross flows are an order of magnitude larger than official flows - rather than imputing Chinese reserves accumulation to financing the US current account deficit, one could equally well (or poorly) argue that they are financing FDI flows to emerging markets, including China. Third, the role of official interventions was most important at a time when the US was experiencing a temporary slowdown, while our analysis refers to more persistent trends.
} 


\section{A Model with Explicit Asset Supply Constraints}

In this section we develop a stylized model that endogenizes and captures the broad patterns of capital flows, interest rates and global portfolios shown in Figure 1. The model highlights the supply side of the market for global saving instruments. We slice the world into three groups: $U$-countries have deep financial markets and good growth conditions; $E$-countries have deep financial markets but (perhaps temporarily) bad growth conditions; finally, $R$-countries (perhaps temporarily) do not have deep financial markets but have exceptional growth conditions.

In this context we show that both the depressed growth conditions in $E$ and the depressed financial markets in $R$ compound to generate large and persistent capital flows to $U$. Moreover, the exceptional growth conditions in $R$ exacerbate rather than offset this pattern. ${ }^{4}$

After a series of preliminaries explaining the essence of our framework, we split the argument into three parts. In the first one, we study global equilibrium in a world with $U$ and $E$ countries only. This is the closest to the conventional analysis and has the dual role of showing the workings of our model and studying the equilibrium impact of a persistent decline in E's growth conditions, as experienced by Japan from the early 1990s and Continental Europe more recently. This decline raises capital flows from $E$ to $U$ and lowers global interest rates almost indefinitely. That is, the automatic rebalancing forces, regardless of the extent of home-bias, are tenuous in the absence of a reversal in the factors that led to the original imbalances, namely depressed growth conditions in $E$.

In the second part we study global equilibrium in a world with $U$ and $R$ countries only. This is the core of our model. We first show that if $R$ 's capacity to generate reliable financial assets crashes, global interest rates drop and capital flows from $R$ to $U$ permanently. Moreover, if growth potential in $R$ is above that of the rest of the world, both effects are exacerbated. In particular, long run rates decline by more than short rates, and $U$ can finance very significant current account deficits indefinitely. That is, if the initial asymmetry in financial development is not undone, the automatic rebalancing forces are even more tenuous than in the $U-E$ world. This part primarily captures the events following the Asian and Russian crises, as well as the fast growth and (favorably) high commodity prices experienced by much of the $R$ region shortly afterwards. It also captures some of the elements following the crash of the Japanese bubble in the early 1990s.

We close this section by integrating the three regions. Aside from adding the effects of the previous two parts, we show that the shock in $R$ has a larger (favorable) impact on $U$ than on $E$. The reason is that the

\footnotetext{
${ }^{4}$ Thus, the view that growth of US trading partners is on average similar to that of the US, so that differential growth cannot be a factor in explaining the large capital flows to the US, is misguided from our perspective. It matters a great deal who is growing faster and who is growing slower than the US. If those that compete with the US in asset production grow slower and those that demand assets grow faster, then both factors play in the same direction.
} 
lower interest rates resulting from the asset markets collapse in $R$ has a larger positive effect on asset values in the region with better growth prospects.

\subsection{Preliminaries}

\subsubsection{A closed economy}

Time evolves continuously. Infinitesimal agents (traders) are born at a rate $\theta$ per unit time and die at the same rate; population mass is constant and equal to one. At birth, agents receive a perishable endowment of $(1-\delta) X_{t}$ which they save in its entirety until they die (exit). Agents consume all their accumulated resources at the time of death. The term $(1-\delta) X_{t}$ should be interpreted as the share of national output that is not capitalizable.

The only saving vehicles are identical "trees" producing in aggregate a dividend of $\delta X_{t}$ per unit time. Agents can save only in local trees.

By arbitrage, the instantaneous return from hoarding a unit of a tree, $r_{t}$, satisfies:

$$
r_{t} V_{t}=\delta X_{t}+\dot{V}_{t}
$$

where $V_{t}$ is the value of the trees at time $t$. As is standard, the return on the tree equals the dividend price ratio $\delta X_{t} / V_{t}$ plus the capital gain $\dot{V}_{t} / V_{t}$.

Let $W_{t}$ denote the savings accumulated by active agents at date $t$. Savings decrease with withdrawals (deaths), and increase with the endowment allocated to new generations and the return on accumulated savings:

$$
\dot{W}_{t}=-\theta W_{t}+(1-\delta) X_{t}+r_{t} W_{t}
$$

In equilibrium, savings must be equal to the value of the trees:

$$
W_{t}=V_{t}
$$

Replacing (3) into (1), and the result into (2), yields a relation between savings and production: ${ }^{5}$

$$
W_{t}=\frac{X_{t}}{\theta}
$$

Replacing this expression back into (1), using (3), we obtain an expression for the instantaneous equilibrium interest rate:

$$
r_{t}=\frac{\dot{X}_{t}}{X_{t}}+\delta \theta
$$

\footnotetext{
${ }^{5}$ By Walras' Law, noticing that $\theta W_{t}$ corresponds to consumption, we can re-write this relation as a goods-market equilibrium condition:

$$
\theta W_{t}=X_{t}
$$
}


Conditional on exogenous output $X_{t}$, the interest rate rises with growth because the latter lifts the rate of growth of financial wealth demand $(W)$, and hence the expected capital gains from holding a tree; it rises with $\delta$ because this increases the share of income that is capitalizable and hence it raises the supply of assets ${ }^{6}$ and it rises with $\theta$ because this lowers financial wealth demand and hence asset prices. ${ }^{7}$

We assume that the total endowment in the economy, $X_{t}$, grows at rate $g$. Hence $r_{t}$ is given by $r_{\text {aut }}$ where

$$
r_{\text {aut }}=g+\delta \theta
$$

\subsubsection{A Small Open Economy}

Let us now open the (small) economy, which faces a given world interest rate, $r$, such that:

Assumption $1 g<r<g+\theta$

Definition 1 (Trade Balance and Current Account): Let us denote the trade balance and current account at time $t$ as $T B_{t}$ and $C A_{t}$, respectively, with:

$$
\begin{aligned}
T B_{t} & \equiv X_{t}-\theta W_{t} \\
C A_{t} & \equiv \dot{W}_{t}-\dot{V}_{t}
\end{aligned}
$$

The definition of the trade balance is standard. The current account is also standard. It is the dual of the financial account and is defined as the increase in the economy's net asset demand.

To find the steady state of this economy, we integrate (1) forward and (2) backward:

$$
\begin{aligned}
V_{t} & =\int_{t}^{\infty} \delta X_{s} e^{-r(s-t)} d s \\
W_{t} & =W_{0} e^{(r-\theta) t}+\int_{0}^{t}(1-\delta) X_{s} e^{(r-\theta)(t-s)}
\end{aligned}
$$

\footnotetext{
${ }^{6}$ Given our particular parametrization, a rise in $\delta$ also lowers asset demand. This effect reinforces our asset supply mechanism but it is not robust to alternative parametrizations.

${ }^{7}$ Note that (5) differs from the usual equation that would prevail if we were to adopt the standard frictionless infinite horizon consumption model. There, the interest would be determined entirely by the (asset) demand side: it would depend only on consumption growth, the rate of time preference and the elasticity of intertemporal substitution. Hence, $\delta$, which parameterizes the supply of financial assets, would play no role. The reason is that in the standard frictionless infinite horizon model, a reduction in $\delta$ changes the relative importance of financial to human wealth, without changing total wealth and hence consumption. That is, as we reduce $\delta$, the drop in financial savings - the demand for financial assets - exactly offsets the drop in financial asset supply, leaving the interest rate unaffected. Thus, in order to introduce an equivalent role for supply of financial assets in that model, we would have to introduce collateral constraints and link collateral to capitalizable income. Our preferences and demographic assumptions achieve the same more efficiently.
} 


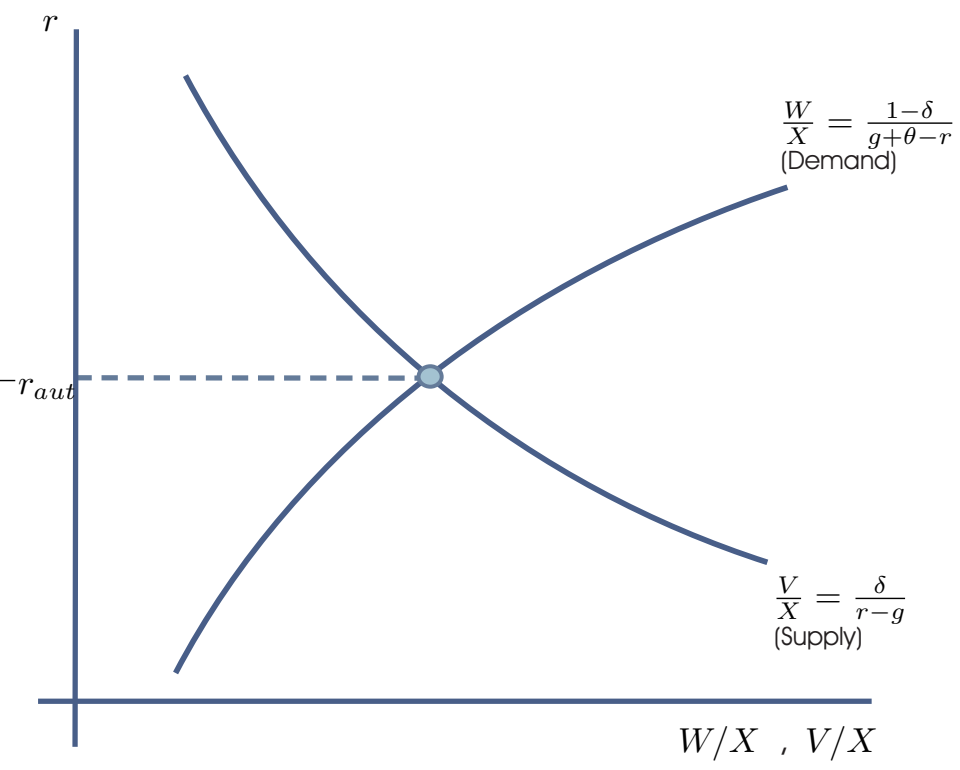

Figure 2: The Metzler diagram.

Assumption 1 implies that asymptotically

$$
\begin{aligned}
& \frac{V_{t}}{X_{t}} \underset{t \rightarrow \infty}{\rightarrow} \frac{\delta}{r-g} \\
& \frac{W_{t}}{X_{t}} \underset{t \rightarrow \infty}{\rightarrow} \frac{1-\delta}{g+\theta-r}
\end{aligned}
$$

Equation (6) is just Gordon's formula. It shows that the asymptotic supply of assets, normalized by the size of the economy, is a decreasing function of $r$. Equation (7) describes the asymptotic demand for assets which, normalized by the size of the economy, is an increasing function of $r$. Figure 2 represents the equilibrium in a supply and demand diagram, a variation on the Metzler diagram. The supply curve and demand curve cross at $r=r_{a u t}$.

$$
\text { If } r<r_{a u t} \quad \frac{\delta}{r-g}>\frac{1-\delta}{g+\theta-r}
$$

and domestic asset supply exceeds demand. Since along the balanced growth path $\dot{W}_{t}=g W_{t}$ and $\dot{V}_{t}=g V_{t}$, the above inequality implies that the small country runs an asymptotic current account deficit (financed by an asymptotic capital account surplus):

$$
\frac{C A_{t}}{X_{t}} \underset{t \rightarrow \infty}{\rightarrow} g\left(\frac{1-\delta}{g+\theta-r}-\frac{\delta}{r-g}\right)=-g \frac{\left(r_{a u t}-r\right)}{(g+\theta-r)(r-g)} .
$$

Note also that, asymptotically, the trade balance is in surplus: The lower rate of return on savings depresses wealth accumulation and, eventually, consumption

$$
\frac{T B_{t}}{X_{t}} \underset{t \rightarrow \infty}{\rightarrow} \frac{r_{a u t}-r}{g+\theta-r}
$$


Importantly, however, this asymptotic trade surplus is not enough to service the accumulated net external liabilities of the country, which is why the current account remains in deficit forever.

Conversely, note that when $r>r_{\text {aut }}$, (8) and (9) still hold, but now the economy runs an asymptotic current account surplus.

We can prove a stronger result that will be useful later on.

Lemma 1 Consider a path for the interest rate $\left\{r_{t}\right\}_{t \geq 0}$ such that $\lim _{t \rightarrow \infty} r_{t}=r$ with $g<r<g+\theta$. Then

$$
\begin{aligned}
& \frac{V_{t}}{X_{t}} \underset{t \rightarrow \infty}{\rightarrow} \frac{\delta}{r-g}, \quad \frac{W_{t}}{X_{t}} \underset{t \rightarrow \infty}{\rightarrow} \frac{1-\delta}{g+\theta-r} \\
& \frac{C A_{t}}{X_{t}} \underset{t \rightarrow \infty}{\rightarrow}-g \frac{\left(r_{\text {aut }}-r\right)}{(g+\theta-r)(r-g)}, \quad \frac{T B_{t}}{X_{t}} \underset{t \rightarrow \infty}{\rightarrow} \frac{r_{a u t}-r}{g+\theta-r}
\end{aligned}
$$

Proof. See the appendix.

\subsection{A World with Symmetric (and Developed) Financial Markets (A $U-E$ World)}

Let us now study global equilibrium with two large regions, $i=\{U, E\}$. Each of them is described by the same setup as in the closed economy, with an instantaneous return from hoarding a unit of either tree, $r_{t}$, which is common across both regions and satisfies:

$$
r_{t} V_{t}^{i}=\delta X_{t}^{i}+\dot{V}_{t}^{i}
$$

where $V_{t}^{i}$ is the value of country $i$ 's tree at time $t$. Let $W_{t}^{i}$ denote the savings accumulated by active agents in country $i$ at date $t$ :

$$
\dot{W}_{t}^{i}=-\theta W_{t}^{i}+(1-\delta) X_{t}^{i}+r_{t} W_{t}^{i}
$$

Adding (10) and (11) across both regions, yields:

$$
\begin{gathered}
r_{t} V_{t}=\delta X_{t}+\dot{V}_{t} \\
\dot{W}_{t}=-\theta W_{t}+(1-\delta) X_{t}+r_{t} W_{t}
\end{gathered}
$$

with

$$
W_{t}=W_{t}^{U}+W_{t}^{E}, \quad V_{t}=V_{t}^{U}+V_{t}^{E}, \quad X_{t}=X_{t}^{U}+X_{t}^{E} .
$$

From now on, the solution for global equilibrium proceeds exactly as in the closed economy above, with

$$
\theta W_{t}=X_{t}
$$

and

$$
r_{t}=\frac{\dot{X}_{t}}{X_{t}}+\delta \theta
$$

Let us now specify the initial conditions and follow with our first shock. 
Assumption 2 (Initial Conditions): The world is initially symmetric, with equal levels of $X_{t}^{i}$ and a constant rate of growth, common to both countries, $g$. There are no (net) capital flows across the economies and $W_{t}^{U}=V_{t}^{U}=V_{t}^{E}=W_{t}^{E}$.

Suppose now that, unexpectedly, at $t=0$, the rate of growth of $E$ drops permanently to

$$
g^{E}<g
$$

Lemma 2 (Continuity): At impact, $r$ absorbs the shock while $V$ and $W$ remain unchanged.

Proof. At any point in time, it must be true that

$$
W_{t}=\frac{X_{t}}{\theta}
$$

It follows that $W_{t}$ does not jump at $t=0: W_{0-}=W_{0+}=X_{0} / \theta$. Since $W_{t}=V_{t}$ must hold at all times, we conclude that $V_{t}$ does not jump either: $V_{0-}=V_{0+}=X_{0} / \theta$. But for this absence of a decline in $V$ at impact to be consistent with the asset pricing equation, the growth slowdown in $E$ must be offset by a drop in $r$ :

$$
r_{0+}=\frac{g+g^{E}}{2}+\delta \theta<r_{0-}=g+\delta \theta
$$

that reflects a decline in world output growth. ${ }^{8}$

While global wealth and capitalization values do not change at impact, the allocation of these across economies does. On one hand, it stands to reason that the lower growth in $X_{t}^{E}$ implies that $V_{0}^{U} / V_{0}^{E}$ must rise since both dividend streams are discounted at the common global interest rate. On the other, whether $W_{0}^{U} / W_{0}^{E}$ rises or not depends on the agents' initial portfolio allocations. However, as long as there is some home bias in these portfolios, $W_{0}^{U} / W_{0}^{E}$ rises as well. Because the conventional view has taken the well established fact of home bias as a key force bringing about rebalancing of portfolios, we shall assume it as well, as this isolates the contribution of our mechanisms more starkly. Moreover, for clarity, in the main propositions we assume an extreme form of home bias, but then extend the simulations and figures to other cases.

Assumption 3 (Home Bias). Agents first satisfy their saving needs with local assets and only hold foreign assets once they run out of local assets.

This assumption implies that, at impact, local wealths' changes match the changes in the value of local trees one-for-one:

$$
\begin{aligned}
& W_{0+}^{E}-\frac{W_{0}}{2}=V_{0+}^{E}-\frac{V_{0}}{2} \\
& W_{0+}^{U}-\frac{W_{0}}{2}=V_{0+}^{U}-\frac{V_{0}}{2}
\end{aligned}
$$

\footnotetext{
${ }^{8}$ According to the World Development Indicators, average output growth for $U, E$ and $R$ was $3.41 \%$ in the 1980 s, $2.77 \%$ in the 1990 s and $2.75 \%$ since 2000 .
} 
These changes in wealth have a direct impact on consumption, which are reflected immediately in the trade balance and current account.

Before describing these effects, let us digress momentarily. At times, it will be convenient for exposition to note that the current account can also be written as the sum of trade balance and net income from global holdings:

Lemma 3 (Alternative Formulation of the Current Account)

$$
\begin{aligned}
C A_{t}^{i} & =X_{t}^{i}-\theta W_{t}^{i}+r_{t}\left(\alpha_{t}^{i, j} V_{t}^{j}-\alpha_{t}^{j, i} V_{t}^{i}\right) \\
& =T B_{t}^{i}+r_{t}\left(\alpha_{t}^{i, j} V_{t}^{j}-\alpha_{t}^{j, i} V_{t}^{i}\right)
\end{aligned}
$$

where $i \neq j, \alpha_{t}^{i, j}$ is the share of country $j$ 's trees held by agents in country $i, \alpha_{t}^{j, i}$ is the share of country $i$ 's trees held by agents in country $j$.

Proof. See the appendix.

Note that our current account definition excludes, as does national accounts, unexpected valuation effects (unexpected capital gains and losses from international positions). This is not a relevant issue for now since the only surprise takes place at date 0 , when agents are not holding international assets. We shall return to this issue when relevant.

Also note that since $C A_{t}^{E}+C A_{t}^{U}=0$, we only need to describe one of the current accounts to characterize both. Henceforth, we shall describe the behavior of $C A_{t}^{U}$, with the understanding that this concept describes features of the global equilibrium rather than $U$-specific features.

Finally, without any substantive implication (see the Appendix for the general case), we make an assumption to narrow the asymptotic cases we need to analyze:

Assumption 4 (Bounded Growth Decline): $\left(g-g^{E}\right)<(1-\delta) \theta$.

Proposition 1 (Persistent Current Account Deficits in U): Under assumptions 1 to 4, an unexpected and persistent decline in $E$ 's rate of growth from $g$ to $g^{E}<g$, turns $C A_{t}^{U}$ into a deficit at impact and remains in deficit in the long run (although vanishing asymptotically relative to $X_{t}^{U}$ ).

Proof. At impact, we have

$$
\begin{gathered}
W_{0+}^{U}=V_{0+}^{U} \\
C A_{0}^{U}=T B_{0}^{U}=X_{0}^{U}-\theta V_{0+}^{U}<0
\end{gathered}
$$

For $t>0$, using $\theta W_{t}=X_{t}$ and $\theta V_{t}=X_{t}$ we have

$$
C A_{t}^{U}=\dot{W}_{t}^{U}-\dot{V}_{t}^{U}=\dot{V}_{t}^{E}-\dot{W}_{t}^{E}
$$


From equation (15) and $g>g^{E}, \lim _{t \rightarrow \infty} r_{t}=r_{a u t}^{U}$. Lemma 1 shows that

$$
\begin{aligned}
& \frac{V_{t}^{E}}{X_{t}^{E}} \underset{t \rightarrow \infty}{\rightarrow} \frac{\delta}{r_{a u t}^{U}-g^{E}} \\
& \frac{W_{t}^{E}}{X_{t}^{E}} \underset{t \rightarrow \infty}{\rightarrow} \frac{(1-\delta)}{g^{E}+\theta-r_{a u t}^{U}}
\end{aligned}
$$

and

$$
\frac{C A_{t}^{U}}{X_{t}^{E}}=-\frac{C A_{t}^{E}}{X_{t}^{E}} \underset{t \rightarrow \infty}{\rightarrow}-\frac{g^{E}\left(r_{a u t}^{U}-r_{a u t}^{E}\right)}{\left(g^{E}+\theta-r_{a u t}^{U}\right)\left(r_{a u t}^{U}-g^{E}\right)}<0 .
$$

Finally, it follows immediately from $g>g^{E}$ that $C A_{t}^{U} / X_{t}^{U}$ vanishes asymptotically.

The impact effect of a decline in E's rate of growth is a decline in the value of E's assets which drags down E's wealth one for one given the extreme home bias assumption. This leads to an immediate drop in $E$ 's consumption which is not matched by a drop in E's current income. Thus E's trade balance, which is equal to the current account in the symmetric initial equilibrium, goes into surplus. In equilibrium, $U$ has to absorb this surplus by running a trade deficit. The latter is achieved by an increase in $U$ 's consumption, which results from an increase in $U$ 's wealth following the appreciation of $U$ 's assets. This appreciation does not stem from any increase in $U$ 's growth prospects, but from the fall in interest rates brought about by $E$ 's slowdown.

Suddenly $U$ 's assets look relatively more attractive, and hence a share of E's saving begins to flow to these assets. Over time, the return on these assets raises E's wealth and consumption (relative to output), eventually overturning the initial trade surplus, and hence $U$ 's trade deficit.

However, $U$ 's eventual trade surpluses are never enough to service the accumulated net-foreign liabilities in full, and hence $U$ 's current account remains in deficit forever. The counterpart of this persistent deficit is a sustained accumulation of $U$ 's assets by $E$. This accumulation is very fast early on, as the relative importance of $U$ assets in $E$ 's portfolio rises until it converges (asymptotically) to:

$$
\frac{g-g^{E}}{\left((1-\delta) \theta-\left(g-g^{E}\right)\right)\left(\left(g-g^{E}\right)+\delta \theta\right)}>0 .
$$

Thus, in the limit, $E$ continuously accumulates $U$ 's assets at a rate $g^{E}$.

Of course, this does not mean that our model violates the intertemporal approach to the current account. Integrating forward the equation:

$$
\dot{W}_{t}^{U}-\dot{V}_{t}^{U}=X_{t}^{U}-\theta W_{t}^{U}+r_{t}\left(W_{t}^{U}-V_{t}^{U}\right)
$$

we find the usual expression:

$$
\begin{aligned}
W_{t}^{U}-V_{t}^{U} & =-\int_{t}^{\infty}\left(X_{s}^{U}-\theta W_{s}^{U}\right) e^{-\int_{t}^{s} r_{u} d u} d s \\
& =-\int_{t}^{\infty} T B_{s}^{U} e^{-\int_{t}^{s} r_{u} d u} d s .
\end{aligned}
$$


In particular

$$
0=W_{0^{+}}^{U}-V_{0^{+}}^{U}=-\int_{0}^{\infty} T B_{t}^{U} e^{-\int_{0}^{t} r_{s} d s} d t
$$

Since the initial net asset position is balanced in our basic scenario, the net present value of trade balance surpluses is zero. The trade balance $T B_{t}^{U}$ is initially in deficit and eventually turns into surplus since:

$$
\frac{T B_{t}^{U}}{X_{t}^{E}}=-\frac{T B_{t}^{E}}{X_{t}^{E}} \underset{t \rightarrow \infty}{\rightarrow} \frac{g-g^{E}}{g^{E}+\theta-r_{a u t}^{U}}>0 .
$$

Importantly, however, increased net interest payments to $E$ due to $U$ 's accumulation of net foreign liabilities exceed the trade balance surpluses and generate a chronic current account deficit in $U$.

We can understand the asymptotic result in the proposition with reference to the simple small open economy in Section 2.1, and its Figure 2. First, since in the long run $U$ dominates the global economy, the equilibrium interest rate converges to the Autarky interest rate for $U$ :

$$
r_{\infty}=r_{\text {aut }}^{U}=g+\delta \theta
$$

Thus the gap between $W_{t}^{U} / X_{t}^{U}$ and $V_{t}^{U} / X_{t}^{U}$ is asymptotically vanishing. However, note that the limit interest rate exceeds the new Autarky rate in $E$ :

$$
r_{\infty}=g+\delta \theta>g^{E}+\delta \theta=r_{a u t}^{E} .
$$

Thus the asymptotic gap between $W_{t}^{E} / X_{t}^{E}$ and $V_{t}^{E} / X_{t}^{E}$ is strictly positive. Moreover, by global equilibrium this means that the asymptotic gap between $W_{t}^{U} / X_{t}^{E}$ and $V_{t}^{U} / X_{t}^{E}$ is strictly negative.

Let us now turn to a characterization of the entire path. Figure 3 portrays an example of the impact of a growth slowdown for parameters calibrated to match some key aspects of the data. ${ }^{9}$ Our only goal here is to consolidate the insights from the proposition and to argue that the effects we describe are quantitatively significant. We do not attempt to match the exact paths in the data, as that would require additional smoothing mechanisms, such as gradual globalization, and other adjustment costs. Absent these, adjustments are too large at impact and too fast. Still, note that even in this frictionless environment, adjustments are gradual and capital flows remain large many years after the shock. Also note that the cumulative results, which are more robust to the absence of frictions, are large

Panel A of Figure 3 shows that $U$ 's current account/GDP exhibits large initial deficits of 17 percent of output, which converge to zero only gradually. Panel B reports $U$ 's net external position. The growth shock lowers $V^{E}$ relative to $V^{U}$. Since in order to match Figure 1(c), we calibrated $U$ 's assets share in initial global portfolio to $5 \%$ (rather than the $0 \%$ in the proposition), $U$ suffers a small initial valuation loss. ${ }^{10}$ More centrally, the large initial current account deficits worsen rapidly $U$ 's net foreign asset position

\footnotetext{
${ }^{9}$ See the appendix for a discussion of the calibration. The drop in $E$ 's growth rate is about one percent.

${ }^{10}$ That is, the initial jump at $t=0^{+}$reflects the unexpected valuation effect from $U$ 's holdings of $E$ 's asset. Recall that our convention, similar to NIPA or BoP accounting, excludes these valuation effects from the current account.
} 
Panel A: CA/Output

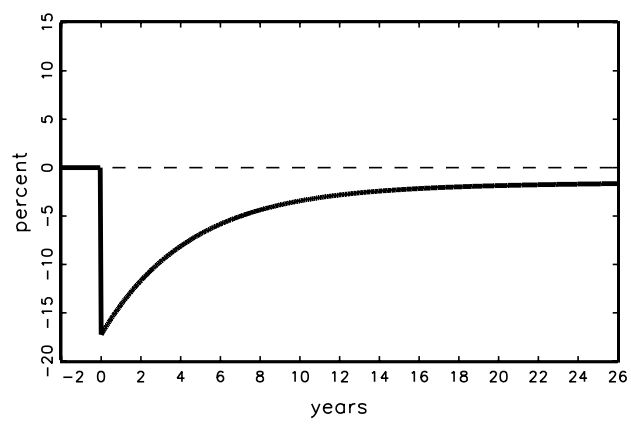

Panel C: Interest Rate

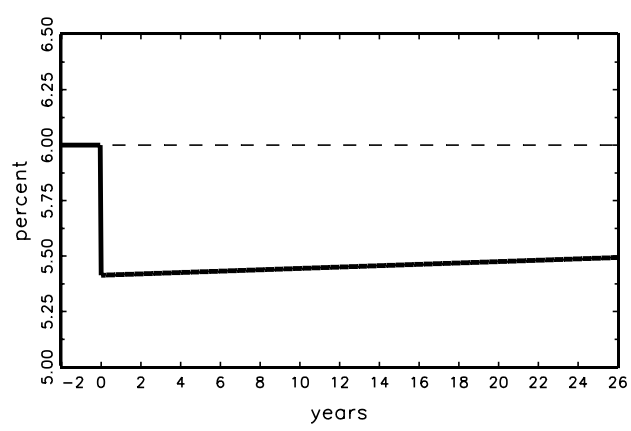

Panel B: Net Foreign Assets/Output

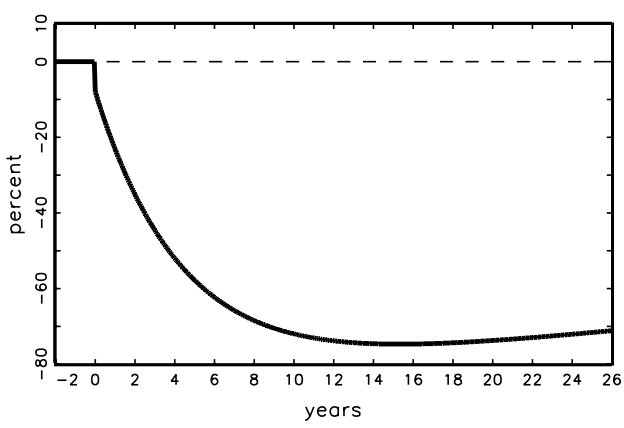

Panel D: Global Portfolio Share

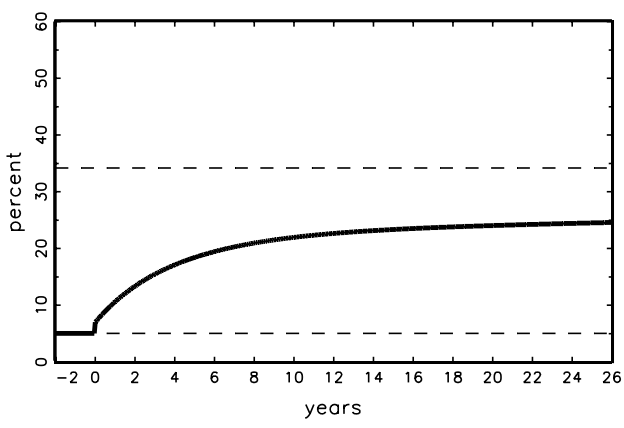

Figure 3: A Collapse in $g^{E}$

from zero to -75 percent in 15 years. Eventually, the net foreign asset position converges to zero (relative to domestic output), but panel B illustrates that this convergence is slow, and in fact comes entirely from the denominator (output growth) since $U$ never runs a current account surplus. Given our parameter values, the initial real interest rate equals 6 percent. Panel $\mathrm{C}$ shows that it drops by about 60 basis points at impact, then climbs back very slowly to pre-shock levels. Finally, the last panel shows the share of $U$ 's assets in $E$ 's wealth, under the assumption that $U$ maintains its initial holdings. This portfolio share increases rapidly from 5 percent to 25 percent, and asymptotes to 34 percent.

The model is thus able to generate simultaneously large and long lasting current account deficits in $U$ (Fact 1); a decline in real interest rates (Fact 2) and an increase in $U$ 's share in the global portfolio (Fact 3).

Up to now, differential growth limited the aggregate ability to create valuable assets in $E$ relative to $U$. But there are other factors that create comparative advantage in asset creation, such as institutional differences, ranging from corporate governance to transparency of the financial system and policymaking. We turn to this analysis next, which is at the core of our explanation for recent global imbalances.

\subsection{A World with Asymmetric Financial Markets (a $U-R$ World)}

Let us now turn to the interaction between $U$ and $R$. For clarity, we shall remove $E$ from the analysis for now. The key element of this part of the model is that $R$ is able to grow and generate income for savers but 
is limited in its ability to generate sound financial assets for these savers.

In this section we develop our argument in two steps: First, at date 0 we let $R$ 's $\delta$ drop from $\delta$ to $\delta^{R}<\delta$, in an environment where $R$ and $U$ are growing at the same rate $g$. Second, we repeat the experiment but now in an environment where $R$ is growing faster than $U, g^{R}>g$.

How should we interpret a drop in $\delta^{R}$ ? In general, as the realization that local financial instruments are less sound than they were once perceived to be. This could result from, inter alia, a crash in a bubble; the realization that corporate governance is less benign than once thought; a significant loss of informed and intermediation capital; the sudden perception — justified or not— of "crony capitalism"; a sharp decline in property rights protection, and so on. All of these factors -and more- were mentioned in the events surrounding the Asian/Russian crises (e.g. Fischer (1998)).

The formulae are very similar to that in the $U-E$ model, but there are some differences that need to be highlighted. Let quantities without superscript denote world aggregates (now made of $U$ and $R$, rather than $U$ and $E$ ), then:

$$
r_{t} V_{t}^{R}=\delta^{R} X_{t}^{R}+\dot{V}_{t}^{R}
$$

and

$$
r_{t} V_{t}=\delta X_{t}-\left(1-x_{t}^{U}\right)\left(\delta-\delta^{R}\right) X_{t}+\dot{V}_{t}
$$

with $x_{t}^{U} \equiv X_{t}^{U} / X_{t}$. Similarly, we have that:

$$
\dot{W}_{t}^{R}=\left(1-\delta^{R}\right) X_{t}^{R}+\left(r_{t}-\theta\right) W_{t}^{R}
$$

and

$$
\dot{W}_{t}=\left[1-\delta+\left(\delta-\delta^{R}\right)\left(1-x_{t}^{U}\right)\right] X_{t}+\left(r_{t}-\theta\right) W_{t}
$$

Finally, using the equilibrium conditions $W=V=X / \theta$, and the arbitrage equation for $V$, we can solve for the equilibrium interest rate as before:

$$
\begin{aligned}
r_{t} & =x_{t}^{U}(g+\delta \theta)+\left(1-x_{t}^{U}\right)\left(g+\delta^{R} \theta\right) \\
& =r_{a u t}^{U}-\left(1-x_{t}^{U}\right)\left(\delta-\delta^{R}\right) \theta .
\end{aligned}
$$

Proposition 2 (Crash in R's Financial Markets with Symmetric Growth): Assume $R$ and $U$ grow at the same rate $g$. Under Assumption 3, if $\delta$ drops in $R$ to $\delta^{R}<\delta$, then the current account of $U$ turns into a deficit at impact and remains in deficit thereafter, with $C A_{t}^{U} / X_{t}^{U}$ converging to a strictly negative constant. The interest rate falls permanently below $r_{\text {aut }}^{U}$.

Proof. Note first that since both regions are growing at the same rate, $x_{t}^{U}=x_{0}^{U}$ for all $t>0$, and the interest rate remains constant after dropping at date 0 : 


$$
r_{t}=r^{+}=r_{a u t}^{U}-\left(1-x_{0}^{U}\right)\left(\delta-\delta^{R}\right) \theta<r_{a u t}^{U}
$$

Next, because the interest rate is constant, the values of the trees change immediately to their new balanced growth path:

$$
V_{t}^{R}=\frac{\delta^{R} X_{t}^{R}}{r^{+}-g}, \quad V_{t}^{U}=\frac{\delta X_{t}^{U}}{r^{+}-g} .
$$

Let us now describe the balanced growth path and then return to describe transitory dynamics. In the balanced growth path, we know from Lemma 1 that

$$
W_{t}^{R}=\frac{\left(1-\delta^{R}\right) X_{t}^{R}}{\theta+g-r^{+}} \quad W_{t}^{U}=\frac{(1-\delta) X_{t}^{U}}{\theta+g-r^{+}}
$$

and

$$
\frac{C A_{t}^{U}}{X_{t}^{U}}=-g \frac{r_{a u t}^{U}-r^{+}}{\left(g+\theta-r^{+}\right)\left(r^{+}-g\right)}<0 .
$$

For transitory dynamics, define $w_{t}^{R}=W_{t}^{R} / X_{t}^{R}$ so that

$$
\dot{w}_{t}^{R}=\left(r^{+}-g-\theta\right) w_{t}^{R}+\left(1-\delta^{R}\right) .
$$

with a balanced growth equilibrium value of $\left(1-\delta^{R}\right) /\left(\theta+g-r^{+}\right)$.

From home-bias Assumption 3 we have that

$$
w_{0+}^{R}=\frac{V_{0+}^{R}}{X_{0}^{R}}<\frac{1-\delta^{R}}{\theta+g-r^{+}}
$$

since $r^{+}<r_{\text {aut }}^{U}$. That is, $w_{t}^{R}$ is below its balanced growth path at $t=0^{+}$.

Since $r^{+}<r_{\text {aut }}^{U}<g+\theta$, we must have $\dot{w}_{t}^{R}>0$ when $w_{t}^{R}$ is below its steady state, or equivalently:

$$
\dot{W}_{t}^{R}>g W_{t}^{R}
$$

Thus we also have that $U$ 's current account $C A_{t}^{U}=\dot{V}_{t}^{R}-\dot{W}_{t}^{R}$ is in deficit - in fact, a larger deficit- before converging to its new balanced growth path.

That is, now even if both regions have similar rates of growth, $U$ runs a permanent current account deficit. The latter is the counterpart of the increasing flow of resources from $R$-savers, who have few reliable local assets to store value and hence must resort to $U$-assets. In balanced growth, $R$-savings grow at the rate of growth of income. If $R$-savings are below (output-detrended) steady state, then the rate of accumulation exceeds the rate of growth of the economy and capital flows toward $U$ grow at a fast rate (faster than $g$ ).

The collapse in $\delta^{R}$ decreases the global supply of assets by reducing the share of $R$ 's income that can be capitalized. As before, the shock is entirely absorbed via a decline in world interest rates, reflecting a decline in the global dividend rate from $\delta$ to $\delta-\left(1-x_{0}\right)\left(\delta-\delta^{R}\right)$. While global wealth and capitalization do not change at impact, the allocation of wealth and assets across countries does. The collapse in $\delta^{R}$ implies 


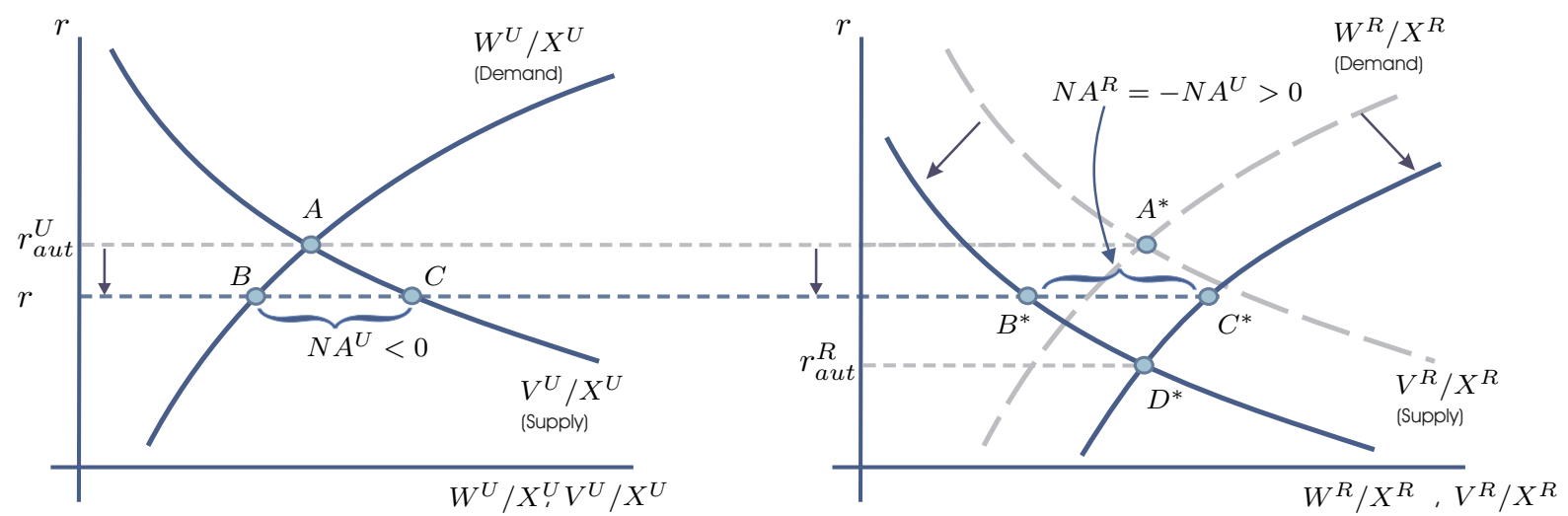

Figure 4: The Metzler diagram for a permanent drop in $\delta^{R}$.

that $V_{0}^{U} / V_{0}^{R}$ must rise as an unchanged stream of $U$ 's dividends is now discounted at a lower interest rate. Correspondingly, under our home bias assumption, the ratio $W_{0}^{U} / W_{0}^{R}$ must also rise. ${ }^{11}$

Again, we can resort to the analysis of a small open economy in Section 2.1, and its Figure 2, to understand the asymptotic result. For this, note that the equilibrium interest rate falls to a level in between the two ex-post Autarky rates:

$$
r_{\text {aut }}^{U}=g+\delta \theta>r^{+}=g+\delta \theta-\left(1-x_{0}^{U}\right)\left(\delta-\delta^{R}\right) \theta>g+\delta^{R} \theta=r_{a u t}^{R}
$$

Thus the gap between $W_{t}^{U} / X_{t}^{U}$ and $V_{t}^{U} / X_{t}^{U}$ is negative and non-vanishing (see Lemma 1). Or, from the other region's perspective, the gap between $W_{t}^{R} / X_{t}^{R}$ and $V_{t}^{R} / X_{t}^{R}$ is positive and non-vanishing. Figure 4 presents the asymptotic result. Starting from a symmetric equilibrium at $A$ and $A^{*}$ with a world interest rate $r_{\text {aut }}^{U}$, the decline in $\delta^{R}$ shifts the $V^{R} / X^{R}$ curve to the left (decline in asset supply) and the $W^{R} / X^{R}$ curve to the right (increase in asset demand). The world interest rate declines just enough so that the net foreign assets in $U\left(N A^{U} \equiv W^{U}-V^{U}<0\right)$ and the net foreign assets in $R\left(N A^{R} \equiv W^{R}-V^{R}>0\right)$ sum to zero.

Figure 5 characterizes the entire path following a collapse of $\delta^{R}$ calibrated so that $R$ 's asset prices drop by $50 \%$ on impact (see the appendix for a discussion). Again, our objective is not to match the precise trajectory of the US current account following the Asian crisis, but to argue that the effects we describe are quantitatively significant. Panel A of Figure 5 shows that $U$ 's current accounts exhibit large initial deficits of 20 percent. The current account remains negative and asymptotes at -2.8 percent of output. As in the $U-E$ case, the large initial current account deficits worsen rapidly the net foreign asset position from -6

\footnotetext{
${ }^{11}$ It is easy to show that if $\delta^{R}$ crashes to zero, then a bubble must arise in $U$-trees. While that drop in $\delta^{R}$ is extreme, it captures the flavor of the behavior of $U$ 's asset markets in recent years. In the less extreme version we have highlighted, we still capture this flavor through the rise in the value of $U$ 's fundamentals following the decline in equilibrium interest rates.
} 

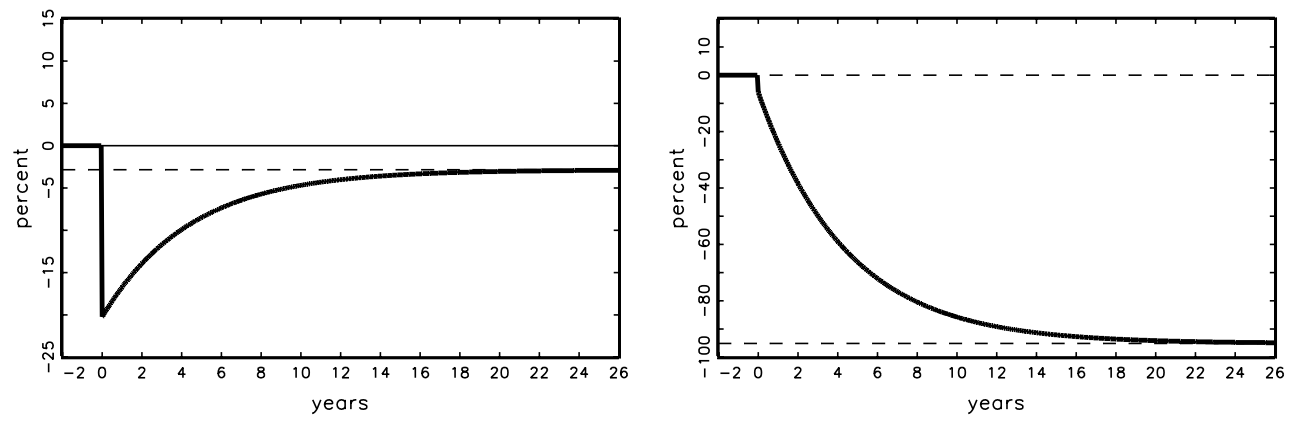

Panel C: Interest Rate

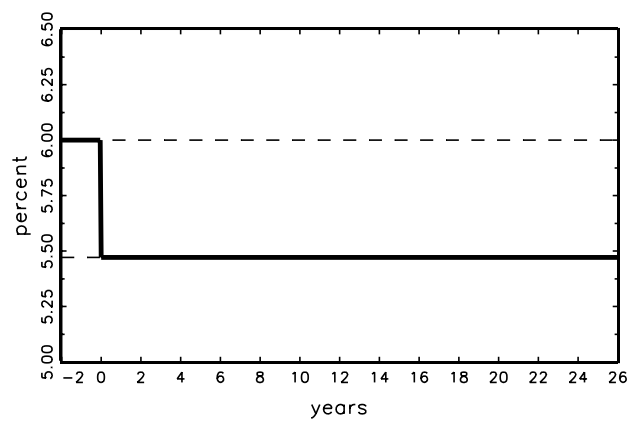

Panel D: Global Portfolio Share

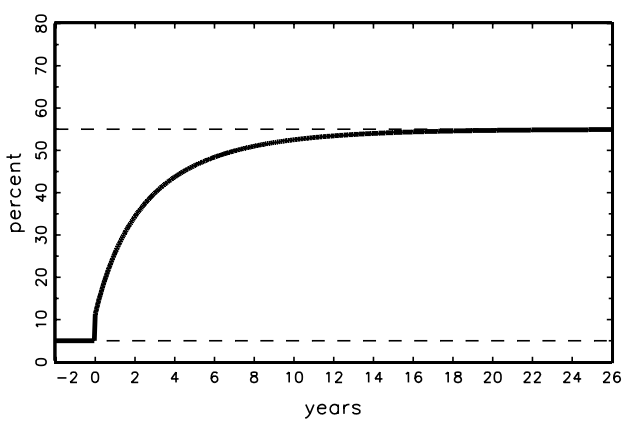

Figure 5: A Collapse in $\delta^{R}$

percent at impact to -95 percent (panel B). The real interest rate drops by slightly more than 50 basis points and remains permanently lower. Finally, $U$ 's share in $R$ 's portfolio increases gradually from 11 percent (immediately after the shock) to 55 percent. ${ }^{12}$

Once again, the model is able to generate, simultaneously, large and long lasting current account deficits in $U$ (Fact 1); a decline in real interest rates (Fact 2) and an increase in the share of $U$ 's assets in global portfolios (Fact 3).

Importantly, now $C A_{t}^{U} / X_{t}^{U}$ does not vanish asymptotically as it converges to:

$$
\frac{C A_{t}^{U}}{X_{t}^{U}}=-g \frac{\left(\delta-\delta^{R}\right)\left(1-x_{0}^{U}\right) \theta}{\left(\theta+g-r^{+}\right)\left(r^{+}-g\right)}<0 .
$$

The reason is that excess savings needs in $R$ grow with $R$ 's output, which grows in tandem with $U$ 's output.

Note also that the size of the permanent current account deficit in $U$ (relative to output) is increasing in the relative size of $R$ (equal to $\left(1-x_{0}^{U}\right)$ ). This observation hints at an important additional source of large and persistent deficits in $U$. In practice, $R$ 's rate of growth exceeds that of $U$, and hence the relative importance of this source of funding of $U$-deficits rises over time - both, because of differential growth and because many $R$ countries are gradually globalizing.

Let us now turn to our second experiment and explore the effect of a crash in $\delta^{R}$ that takes place in an

\footnotetext{
${ }^{12}$ The initial jump from 5 to 11 percent reflects the drop in $R$ 's wealth and jump in $V^{U}$ at $t=0^{+}$.
} 
environment where:

$$
g^{R}>g
$$

The instantaneous interest rate in this case is:

$$
r_{t}=x_{t}^{U}(g+\delta \theta)+\left(1-x_{t}^{U}\right)\left(g^{R}+\delta^{R} \theta\right) .
$$

Let us assume that the additonal growth in $R$ is not enough to offset the effect of a lower $\delta^{R}$ on interest rates:

Assumption 5 (Lower ex-post autarky rate in $R$ ) $\quad r_{a u t}^{R}=g^{R}+\theta \delta^{R}<r_{a u t}^{U}-\theta\left(1-x_{0}^{U}\right)\left(\delta-\delta^{R}\right)<r_{\text {aut }}^{U}$

Proposition 3 (Crash in R's Financial Markets with High Growth in R) Suppose that Assumptions 3 and 5 hold, but that $g^{R}>g$. If at date $0 \delta$ drops to $\delta^{R}$ in $R$, then:

$$
r_{a u t}^{U}=r_{0^{-}}>r_{0^{+}}>r_{\infty}=r_{a u t}^{R}
$$

and the asymptotic current account deficit in $U$ relative to its output is larger when $g^{R}>g$ than when $g^{R}=g:$

$$
\lim _{\substack{t \rightarrow \infty \\ g^{R}>g}} \frac{C A_{t}^{U}}{X_{t}^{U}}<\lim _{\substack{t \rightarrow \infty \\ g^{R}=g}} \frac{C A_{t}^{U}}{X_{t}^{U}}<0
$$

Proof. See the appendix.

The result in this proposition is intuitive given the previous proposition: As $R$ 's growth rises, so does its demand for financial assets. Since this rise is not matched by an increase in $R$ 's ability to generate financial assets, these assets must be found in $U$ and interest rates drop as the price of $U$-assets rise. The corresponding increase in capital flows finances the larger current account deficit in $U$. Long run interest rates fall more than the short term interest rates because the relative importance of the country with excess demand for assets, $R$, rises over time.

As before, let us now describe the asymptotic result in terms of Figure 2, from Section 2.1. First, since in the long run $R$ dominates the global economy when $g^{R}>g$, the equilibrium interest rate converges to the Autarky interest rate for $R$ :

$$
r_{\infty}=r_{\text {aut }}^{R}=g^{R}+\delta^{R} \theta .
$$

Thus, relative to $X_{t}^{R}$, the gap between $W_{t}^{R}$ and $V_{t}^{R}$ is vanishing, and so is that between $W_{t}^{U}$ and $V_{t}^{U}$.

However, note that this limit interest rate is below the Autarky rate in $U$ :

$$
r_{\infty}=g^{R}+\delta^{R} \theta<g+\delta \theta=r_{\text {aut }}^{U} .
$$

Thus, relative to $X_{t}^{U}$, the gap between $W_{t}^{U}$ and $V_{t}^{U}$ is negative and not vanishing. Moreover, since

$$
r_{\infty}<r^{+}<r_{a u t}^{U},
$$

that gap is larger when $g^{R}>g$ than when $g^{R}=g$. 


\subsection{The Three Regions World $(U-E-R)$}

In this section, we consider a $U-E-R$ environment. Much of this world is simply the sum of the two sub-worlds described above, but there is one additional insight: If the crash in $\delta^{R}$ takes place when $g^{U}>g^{E}$, then the asset appreciation in $U$ is (much) larger than that in $E$, and the bulk of the capital flows from $R$ are directed to $U$ rather than to $E$.

Since the dynamic equations follow directly from those discussed above, we relegate them to the appendix and state the main proposition directly, after making an assumption on the parameter region under consideration:

Assumption $6 r_{a u t}^{R} \equiv g^{R}+\delta^{R} \theta<r_{a u t}^{U} \equiv g+\delta \theta, r_{a u t}^{R}<g^{E}+\theta, g^{E}<g$.

Proposition 4 (Disproportionate Flows toward U) If Assumption 6 holds, then a crash in $\delta^{R}$ leads to an increase in $V^{U} / V^{E}$ and a "disproportionate" (to relative output) allocation of $R$ 's capital outflows to $U$ over E. Asymptotically

$$
\frac{\frac{\delta^{R}}{V_{t}^{U}} \frac{\partial V_{t}^{U}}{\partial \delta^{R}}}{\frac{\delta^{R}}{V_{t}^{E}} \frac{\partial V_{t}^{E}}{\partial \delta^{R}}}=\frac{r_{\infty}-g^{E}}{r_{\infty}-g}=1+\frac{g-g^{E}}{r_{\infty}-g}>1 .
$$

Proof. See the appendix.

In words, the reduction in world interest rates stemming from the crash in $\delta^{R}$ has a larger impact on $U$-assets since these are more leveraged than $E$-assets when $g>g^{E}$. This difference can be quite large. For a decline in $\delta^{R}$ calibrated so that $V^{R}$ collapses by 50 percent on impact, with $g=g^{R}$ and a 1.1 percent growth differential $g-g^{E}$, the ratio of asset price elasticities equals 1.43 .

Figure 6 traces the entire path in the case where $g=g^{R}$. We start the economy in a symmetric equilibrium $\left(g^{i}=g\right.$ and $\left.\delta^{i}=\delta\right)$, with $x_{0}^{U}=x_{0}^{E}=0.425$ and $x_{0}^{R}=0.15$. We then reduce $E$ 's growth at $t=0$. This reduces world interest rates to $5.5 \%$ and increases asset values in $R$ and $U$ as both regions receive capital inflows (panel D). Then, at $t=5$, we decrease $\delta^{R}$. Panel D illustrates that the collapse in $\delta^{R}$ and $V^{R}$ disproportionately affects $V^{U}$ relative to $V^{E}: V^{U}$ increases by 12 percent at $t=5$, compared to 8 percent for $V^{E}$. This results in much larger current account deficits in $U$ relative to $E$ and an additional build-up in net liabilities in $U$ (panel A).

\section{Foreign Direct Investment, Excess Returns, and Persistent Trade Deficits}

Let us now add an investment margin to the $U-R$ model and a reason for foreign direct investment (FDI). We capture the former with the emergence of options to plant new trees over time, and the latter with $U$ 's 
Panel A: CA/Output

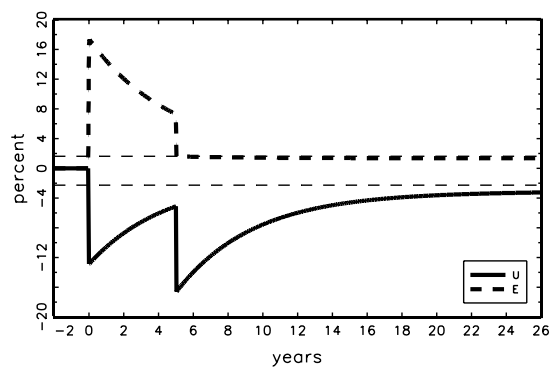

Panel C: Interest Rate

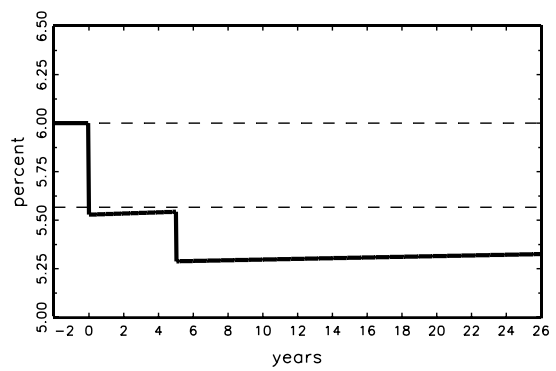

Panel B: Net Foreign Assets/Output

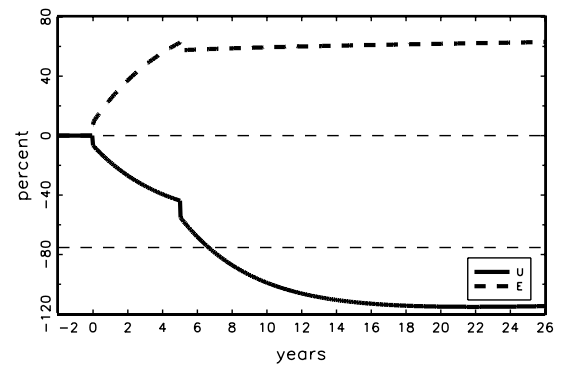

Panel D: Asset/Output

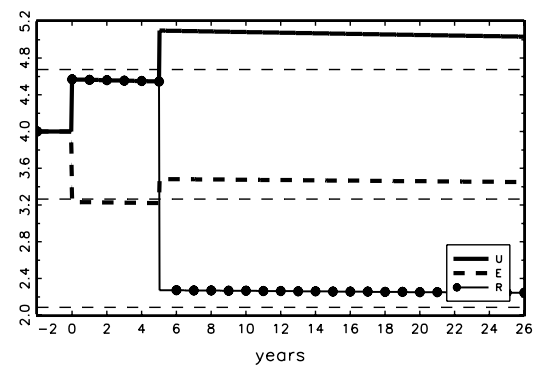

Figure 6: A Collapse in $g^{E}$ followed by a collapse in $\delta^{R}$ in the U-E-R model

ability to convert new $R$ trees into $\delta$ (rather than $\delta^{R}$ ) trees. ${ }^{13}$ The intermediation rents from FDI reduce the trade surpluses that $U$ needs to generate to repay for its persistent early deficits. In fact, we show a stronger result: As long as there are no FDI obstacles (in the sense that all investment can be done by $U$ ) and there is any rent for $U$ 's intermediation service, $U$ will run permanent trade deficits. ${ }^{14}$

\subsection{An Investment Margin}

Let us split aggregate output in each region into the number of trees, $N$, and the output per tree, $Z$ :

$$
X_{t}^{i}=N_{t}^{i} Z_{t}^{i}
$$

\footnotetext{
${ }^{13}$ Note that in a three regions version of the model $E$ also could convert $R$ trees. Although in this case, a good question is which rate of growth would the output of those trees have.

${ }^{14}$ The view here is not unrelated to that in Despres, Kindleberger and Salant (1966) and Kindleberger (1965), who during the Bretton Woods era argued that the US had a unique role as a provider of international currency liquidity. More recently, Gourinchas and Rey (forthcoming 2006) have documented that the total return on US gross assets (mostly equity and FDI) consistently exceeded the total return on gross liabilities (mostly safe instruments) by an average of 3.32 percent per year since 1973. Of course part of this excess return is due to the risk-premium differential associated to the leveraged nature of US investments. Our analysis omits this risk dimension and focus on the "intermediation" rent obtained by the US.

Everything suggests that this "intermediation" role of the US has only grown in importance as total gross capital flows to/from the US have risen from $\$ 222$ billion in 1990 to $\$ 2.3$ trillion in 2004 (see BEA, US International Transactions Accounts, Table 1). See also Lane and Milesi-Ferretti (forthcoming 2006) for a systematic analysis of cross border flows and positions for a large sample of countries.
} 
At each point in time, $g^{n} N_{t}^{i}$ options to plant new trees arise. At the same time, the output of each planted tree grows at the rate $g^{z}$. Planting the $g^{n} N_{t}^{i}$ new trees consumes resources $I_{t}^{i}$ :

$$
I_{t}^{i}=\kappa X_{t}^{i}
$$

We shall assume that $\kappa$ is low enough so that all investment options are exercised (see below), and hence aggregate output grows at rate $g$, with (equal for both regions):

$$
g=g^{n}+g^{z}
$$

Suppose first that $\delta^{i}$ is specific to the region where the tree is planted, not to who planted it. Then

$$
r_{t} V_{t}^{i}=\delta^{i} X_{t}^{i}+\dot{V}_{t}^{i}-g^{n} V_{t}^{i}
$$

where $V_{t}^{i}$ represents the value of all (new and old) trees planted at time $t$ in region $i$, and $\dot{V}_{t}^{i}-g^{n} V_{t}^{i}$ represents the expected capital gains from those trees.

The options to invest are allocated to all those alive at time $t$ within each region, who immediately exercise them by investing $I_{t}^{i} \cdot{ }^{15}$ Thus,

$$
\dot{W}_{t}^{i}=\left(r_{t}-\theta\right) W_{t}^{i}+\left(1-\delta^{i}\right) X_{t}^{i}+g^{n} V_{t}^{i}-I_{t}^{i} .
$$

As usual, aggregating across both regions to find the equilibrium interest rate, yields:

$$
\begin{gathered}
r_{t} V_{t}=\delta X_{t}-\left(\delta-\delta^{R}\right) X_{t}^{R}+\dot{V}_{t}-g^{n} V_{t} \\
\dot{W}_{t}=\left(r_{t}-\theta\right) W_{t}+(1-\delta) X_{t}+\left(\delta-\delta^{R}\right) X_{t}^{R}+g^{n} V_{t}-I_{t}
\end{gathered}
$$

so that:

$$
W_{t}=V_{t}=(1-\kappa) \frac{X_{t}}{\theta}
$$

and

$$
r=g^{z}+\frac{\theta}{1-\kappa}\left(\delta-\left(\delta-\delta^{R}\right) x^{R}\right)<r_{a u t}^{U}=g^{z}+\frac{\theta \delta}{1-\kappa},
$$

which amounts to the same model as in the previous section, with the exceptions that only the rate of growth of output per-tree enters, and that the investment cost reduces wealth accumulation and hence raises the interest rate (since it lowers the price of trees).

\footnotetext{
${ }^{15}$ Note that the share of options that are allocated to existing owners of trees are subsumed within the $Z$ component. In fact, we can reinterpret the model in Section 2 as an investment model where all the options are allocated to the owners of existing trees. The only reason we modified the allocation of options in this section is to spread the excess returns from FDI over time in a more realistic manner (otherwise the entire capitalized excess returns accrues to the first generation in $U$ ).
} 


\subsection{An Intermediation Margin: Foreign Direct Investment}

Let us now assume that $R$ residents can sell the options to the news trees to $U$ residents at price, $P$ :

$$
P_{t}=\kappa_{P} X_{t}^{R n}
$$

where $X_{t}^{R n}$ denotes the output from the trees sold to $U$. We think of this price as the result of some bargaining process but its particular value is not central for our substantive message as long as it leaves some surplus to $U$.

There are gains from trade: If $U$ residents plant the new $R$ trees, the share of output from the new trees that can be capitalized rises from $\delta^{R}$ to $\delta$. Suppose that $P_{t}$ is such that all new $R$ trees are planted by $U$ residents. In fact, the following assumption ensures that $U$ investors and $R$ sellers gain from foreign direct investment along the entire path.

Assumption 7 (Asymptotic Bilateral Private Gains from FDI) Let $\kappa_{P}$ and $\left(\delta-\delta^{R}\right)$ be such that:

$$
g^{n} \frac{\delta}{r_{a u t}-g^{z}}>\kappa+\kappa_{P}>g^{n} \frac{\delta^{R}}{r_{a u t}-g^{z}}
$$

Proposition 5 If Assumption 7 holds, then $U$ runs an asymptotic trade deficit financed by its intermediation rents.

Proof. Let us assume that enough time has passed so that the output of the old $R$ trees is negligible relative to the total output produced by trees planted in $R$ by $U$. We have:

$$
\begin{gathered}
\left(r_{t}+g^{n}\right) V_{t}^{i}=\delta X_{t}^{i}+\dot{V}_{t}^{i} \\
\left(r_{t}+g^{n}\right) V_{t}=\delta X_{t}+\dot{V}_{t} \\
\dot{W}_{t}^{U}=\left(r_{t}-\theta\right) W_{t}^{U}+(1-\delta) X_{t}^{U}+g^{n} V_{t}-\left(I_{t}^{U}+I_{t}^{R}\right)-P_{t} . \\
\dot{W}_{t}^{R}=\left(r_{t}-\theta\right) W_{t}^{R}+(1-\delta) X_{t}^{R}+P_{t} . \\
\dot{W}_{t}=\left(r_{t}-\theta\right) W_{t}+(1-\delta) X_{t}+g^{n} V_{t}-I_{t}
\end{gathered}
$$

so that:

$$
W_{t}=V_{t}=(1-\kappa) \frac{X_{t}}{\theta}
$$

and

$$
r=r_{\text {aut }}=g^{z}+\frac{\delta \theta}{1-\kappa}
$$

It follows from derivations analogous to those in previous sections that:

$$
\frac{W_{t}^{U}}{X_{t}^{U}} \rightarrow \frac{(1-\delta-\kappa)+g^{n} \frac{\delta}{r_{a u t}-g^{z}}+g^{n} \frac{\delta x^{R} / x^{U}}{r_{a u t}-g^{z}}-\left(\kappa+\kappa_{P}\right) x^{R} / x^{U}}{\theta+g-r_{a u t}}
$$


and since $T B_{t}^{U}=-\theta W_{t}^{U}-I_{t}^{U}+X_{t}^{U}$, we have that:

$$
\begin{aligned}
\frac{T B_{t}^{U}}{X_{t}^{U}} & \rightarrow-\theta \frac{(1-\delta-\kappa)+g^{n} \frac{\delta}{r_{a u t}-g^{z}}+g^{n} \frac{\delta x^{R} / x^{U}}{r_{a u t}-g^{z}}-\left(\kappa+\kappa_{P}\right) x^{R} / x^{U}}{\theta+g-r^{U, a u t}}+(1-\kappa) \\
& =-\theta \frac{x^{R}}{x^{U}} \frac{g^{n} \frac{\delta}{r_{a u t}-g^{z}}-\left(\kappa+\kappa_{P}\right)}{\theta+g-r_{\text {aut }}}<0 .
\end{aligned}
$$

That is, the trade balance is in deficit in the long run as long as there is an intermediation rent, which is ensured by Assumption 7 .

Does this mean that the intertemporal approach of the current account has been violated? Certainly not. It simply means that the intermediation rents rather than future trade surpluses pay for the initial (and now permanent) trade deficits. Alternatively, one could account for these intermediation services as "non-traditional" net exports and imports for $U$ and $R$, respectively. In which case, we have:

$$
\widehat{T B}_{t}^{U}=T B_{t}^{U}+g^{n} V_{t}^{R}-\left(\kappa+\kappa_{P}\right) X_{t}^{R}
$$

and, assuming $r_{a u t}>g$ so the integral converges, it follows that:

$$
W_{t}^{U}-V_{t}^{U}=-\int_{t}^{+\infty} \widehat{T B}_{s}^{U} e^{-\int_{t}^{s} r_{u} d u} d s
$$

Figure 7 reports the path of $U$ 's trade balance following a collapse in $\delta^{R} .{ }^{16}$ We consider three cases: first, when $\kappa_{P}$ is sufficiently high that no FDI takes place. Second, when all the rents asymptotically go to $R$ (i.e. when the second inequality of assumption 7 holds exactly) and lastly when all the rents from FDI asymptotically go to $U$ (i.e. when the first inequality of assumption 7 holds exactly). ${ }^{17}$ The model without FDI is very similar to the model of section 2.3: following a collapse in $\delta^{R}$, the interest rate falls permanently from $r_{\text {aut }}$ to $\bar{r}=g^{z}+\bar{\delta} \theta /(1-\kappa)$ where $\bar{\delta}$ is the fraction of world income that can be capitalized. By now, the consequences are well known: the wealth transfer to $U$ generates a trade deficit, an accumulation of foreign debt, eventually followed by trade surpluses (panel D).

In the presence of FDI, the results are starkly different. Let's start with the long run. The asymptotic effect of FDI is to increase the supply of $U$-like assets sufficiently to offset the initial shock. This has a strong implication for the path of net foreign assets (panel B): since $r_{t}$ converges to $r_{a u t}$ as long as FDI takes place (Panel C), the Metzler diagram tells us that long run external imbalances disappear asymptotically. This is independent of the cost of ownership of the $R$ trees $\left(\kappa_{P}\right)$ as long as Assumption 7 is satisfied. The reason is that $\kappa_{P}$ controls the distribution of wealth between $U$ and $R$, leaving total wealth unchanged.

\footnotetext{
${ }^{16}$ We calibrate the decline in $\delta^{R}$ as before, to a drop in $V^{R}$ of $50 \%$. See the appendix for details of the simulation.

${ }^{17}$ For this simulation, we assume $\kappa=0, g^{n}=g=0.03, g^{z}=0$ and we vary $\kappa_{P}$ between $5 \%$ and $12 \%$. For comparability, we also choose $\delta$ so that $r_{\text {aut }}=6 \%$. We obtain $\delta=0.24$.
} 

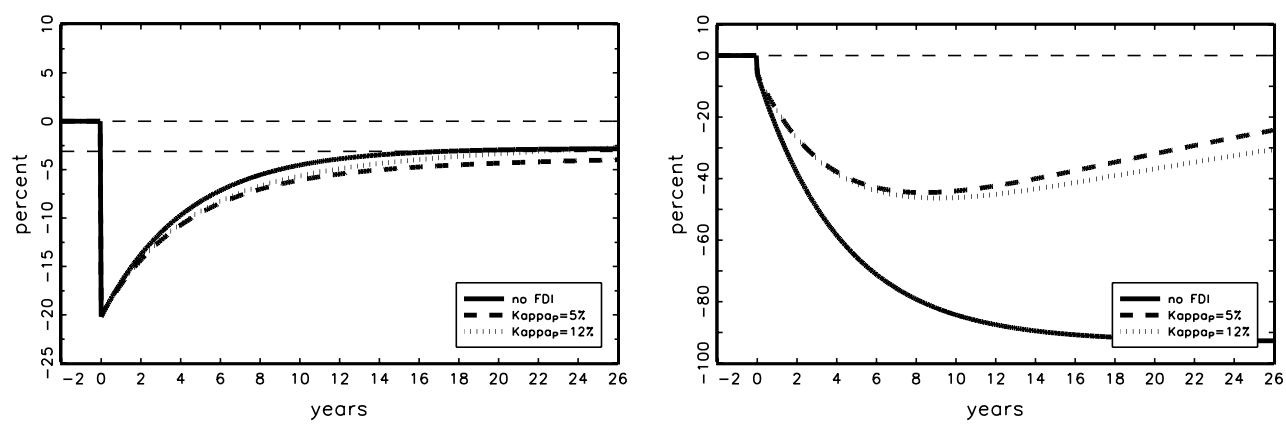

Panel C: World Real Interest Rate

Panel D: Trade Balance/Output
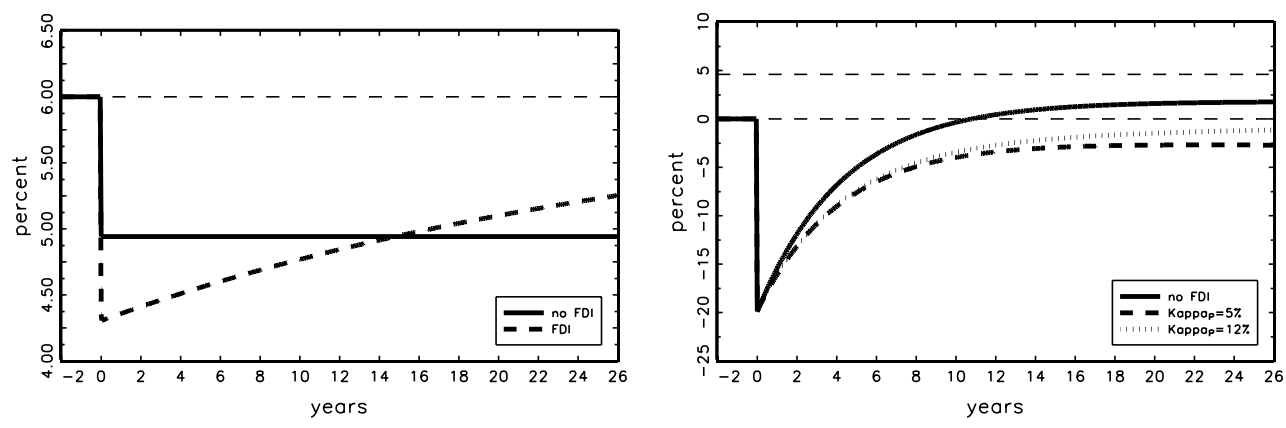

Figure 7: A Collapse in $\delta^{R}$ with and without FDI

Consider the short run now. The interest rate satisfies: ${ }^{18}$

$$
r_{t}=g^{z}+\theta\left[\delta\left(x_{t}^{U}+x_{t}^{R n}\right)+\delta^{R} x_{t}^{R o}\right]-\theta g^{n} \frac{N_{0}^{R}\left[v_{t}^{R n}-v_{t}^{R o}\right]}{X_{t}}
$$

where $x_{t}^{R n}\left(\operatorname{resp} x_{t}^{R o}\right)$ denote the new (resp. old) $R$ 's trees share of world output and $v_{t}^{R n}$ (resp. $v_{t}^{R o}$ ) represent the value of one new (resp. old) $R$ tree. The last term of this equation makes clear that initially $r_{t}<\bar{r}$ since $v_{0}^{R n}>v_{0}^{R o}$ and $x_{0}^{R n}=0$. The reason for this last term is the initial rapid increase in U's asset demand relative to total asset supply when there is FDI $\left(g^{n}\left(V_{t}^{U}+N_{t}^{R} v_{t}^{R n}\right)>g^{n} V_{t}\right)$.

In the short run, FDI increases asset demand -which lowers further interest rates; in the long run, it increases asset supply, which brings interest rates back to $r_{a u t}$.

From (20) and (26) we note also that the dynamics of interest rates and asset values are independent of $\kappa_{P}$ (as long as FDI takes place). Hence, the initial increase in $U$ 's wealth is also independent of the cost of FDI. It follows that $U$ 's initial trade imbalance (equal to $X_{0}^{U}-\theta W_{0}^{U}-I_{0}^{U}$ ) is also independent of $\kappa_{P}$. Indeed, we observe on Panels $\mathrm{A}$ and $\mathrm{D}$ that $U$ 's initial current accounts and trade deficits are the same for different realizations of $\kappa_{P}$.

A lower value of $\kappa_{P}$ (higher rents for $U$ ) implies a permanently larger trade deficit in $U$, ranging from 0 to $4 \%$ of output (Panel D).

\footnotetext{
${ }^{18}$ See the appendix for a derivation.
} 
To understand why $U$ runs asymptotic trade deficits as soon as it has strictly positive asymptotic surpluses, consider first the case where $U$ has no FDI rents asymptotically. In that case, $U$ has no asymptotic trade deficit either. Yet, Panel $\mathrm{D}$ indicates that $U$ never runs a trade surplus. The reason is that $U$ earns rents on its FDI investment along the path, which allow it to run trade deficits in every period. In fact, we can define these rents (over total wealth $W^{U}$ ) as:

$$
\chi_{t}=\frac{g^{n} N_{t}^{R} v_{t}^{R n}-\left(\kappa_{p}+\kappa\right) X_{t}^{R n}-\kappa X_{t}^{R o}}{W_{t}^{U}}
$$

Asymptotically, these rents converge (from above) to

$$
\chi_{\infty}=\left[g^{n} \frac{\delta}{r_{\infty}-g^{z}}-\left(\kappa_{p}+\kappa\right)\right] \frac{X_{t}^{R}}{W_{t}^{U}}
$$

which is equal to zero when the first inequality of assumption 7 holds exactly.

We can now understand why $U$ can run permanent trade deficits: When Assumption 7 holds strictly, intermediation rents remain strictly positive and provide the resources to finance permanent trade deficits.

\section{Multiple Goods and Exchange Rates}

Up to now, our conclusions have abstracted from (real) exchange rate considerations. However, the main point of this section is to show that adding such dimension to the model does not alter the qualitative (and in some cases quantitative) features of the results. While adding multiple goods allows us to generate exchange rate patterns from our shocks that resemble those observed in recent data - in particular, $U$ appreciates vis a vis both, $R$ and (to a lesser extent) $E$, when asset markets collapse in $R$ - the behavior of capital flows and interest rates remain largely unchanged with the exception of some attenuation in the $U-E$ context and amplification in some $U-R$ cases.

\subsection{Preliminaries}

Let us return to the framework in Section 2, without an investment margin, but extend it to consider differentiated goods. Each country $i$ produces one type of good $X^{i}$, while its consumers have the following constant elasticity preferences (CES):

$$
C^{i}=\left(\sum_{j} \gamma_{i j}^{\frac{1}{\sigma}} x^{j \frac{\sigma-1}{\sigma}}\right)^{\frac{\sigma}{\sigma-1}}
$$

where $\sigma$ represents the -constant- elasticity of substitution between the goods from any two countries. The coefficients $\gamma_{i j}$ measure the strength of preferences for the various goods and satisfy $\sum_{j} \gamma_{i j}=1$. Assumption 8 below imposes that agents have a preference for their home good. This assumption is well-established empirically. It also generates relative demand effects that will be important for exchange rate dynamics. 
Assumption 8 (Consumption Home Bias) Each agent has a preference for the home good: $\gamma_{i i} \equiv \gamma>0.5$.

Let $X^{U}$ be the numeraire good and define $q^{j}$ as the price of good $j$ in terms of good $U$ (with the convention $q^{U}=1$ ). Given (28), the Fisher-ideal price indices are:

$$
P^{i}=\left(\sum_{j} \gamma_{i j} q^{j(1-\sigma)}\right)^{1 /(1-\sigma)}
$$

and the real exchange rate between countries $i$ and $k$ is

$$
\lambda^{i k}=\frac{P^{k}}{P^{i}}=\left(\frac{\sum_{j} \gamma_{k j} q^{j(1-\sigma)}}{\sum_{j} \gamma_{i j} q^{j(1-\sigma)}}\right)^{1 /(1-\sigma)}
$$

This expression highlights the importance of consumption home bias for exchange rate movements: if $\gamma_{i j}=$ $\gamma_{k j}$ for all $j$, then purchasing power parity obtains and the real exchange rate is equal to 1.

Given CES preferences, the demand for good $j$ by residents of country $i$ satisfy:

$$
x^{i j}=\gamma_{i j} C^{i}\left(\frac{q^{j}}{P^{i}}\right)^{-\sigma}, \forall i, j
$$

and equilibrium in the goods market imposes

$$
\sum_{i} x_{i j}=X_{j}, \forall j
$$

Substituting $P^{i} C^{i}=\theta W^{i}$ (where domestic wealth is now measured in terms of $U$ 's good), the equilibrium condition for good $i$ can be rewritten as:

$$
\theta \sum_{i} \gamma_{i j} \frac{W^{i}}{P^{i}}\left(\frac{q^{j}}{P^{i}}\right)^{-\sigma}=X^{j}, \forall j .
$$

\subsection{A $U-E$ World}

We now specialize the model to a symmetric $U-E$ world, and denote by $r_{t}$ the instantaneous return in terms of the numeraire. By arbitrage, $r_{t}$ satisfies

$$
r_{t} V_{t}^{i}=\delta q_{t}^{i} X_{t}^{i}+\dot{V}_{t}^{i}
$$

while wealth dynamics follow

$$
\dot{W}_{t}^{i}=(1-\delta) q_{t}^{i} X_{t}^{i}+\left(r_{t}-\theta\right) W_{t}^{i}
$$

As before, adding across countries and using the equality between global wealth and global asset values, one obtains:

$$
W_{t}=V_{t}=\frac{X_{t}}{\theta}
$$


where $X_{t}=X_{t}^{U}+q_{t}^{E} X_{t}^{E}$.

Following the same steps as before, the instantaneous interest rate satisfies:

$$
r_{t}=\frac{\dot{X}_{t}}{X_{t}}+\delta \theta
$$

The only notable difference is that the (inverse of the) terms of trade $q_{t}^{E}$-and hence the real exchange rate- enters into the determination of global wealth and of the equilibrium interest rate via $X_{t}$.

In turn, the terms of trade are determined by the equilibrium on the market for $X^{U}$ (by Walras' Law, the market for $X^{E}$ is also in equilibrium):

$$
\theta \gamma W_{t}^{U} P_{t}^{U(1-\sigma)}+\theta(1-\gamma) W_{t}^{E} P_{t}^{E(1-\sigma)}=X_{t}^{U} .
$$

Let Assumptions 2 and 3 hold, so that the world is initially symmetric with a common rate of growth $g$, and there is extreme portfolio home bias. Given the symmetry assumption, it is immediate that $q^{E}=1$, so that the interest rate satisfies:

$$
r=g+\delta \theta
$$

while asset values and wealth satisfy

$$
V^{i}=W^{i}=\frac{X^{i}}{\theta}
$$

As before, suppose that at $t=0$ the growth rate of $E$ drops unexpectedly and permanently to:

$$
g^{E}<g
$$

The main initial difference with Section 2 is that now both the interest rate and the real exchange rate absorb the shock at impact. To see this, observe that the decline in $g^{E}$ decreases $E$ 's asset values. With Assumption 3 (extreme home portfolio bias), this impoverishes E's residents. Given the consumption-homebias assumption (Assumption 8), the associated decline in E's consumption falls mostly on the demand for $E$ goods. Equilibrium in the goods markets then requires that $q^{E}$ falls. This relative demand effect implies that $U$ 's real exchange rate appreciates at impact. It is a direct consequence of both home consumption and portfolio biases. Over time, however, the increase in the relative supply of $U$ 's good requires that its real exchange rate depreciates.

How large is the initial fall and eventual increase in $q^{E}$ depends on the elasticity of substitution $\sigma$. To see this, observe that the relative demands satisfy

$$
\frac{x^{i E}}{x^{i U}} \propto\left(q^{E}\right)^{-\sigma}
$$

Asymptotically, the ratio of relative demands for at least one country must equal the ratio of relative supply, $X^{E} / X^{U}$. From this, we infer that:

$$
\frac{\dot{q}_{t}^{E}}{q_{t}^{E}} \underset{t \rightarrow \infty}{=} \frac{1}{\sigma}\left(g-g^{E}\right)
$$


Let us rule out the region $\sigma<1$ since it implies immiserizing growth. In the feasible region, consider first the $\sigma=1$ case which yields the starkest departure from the previous section. Given the initial symmetry between $E$ and $U$, one can show that now terms of trade satisfy

$$
q_{t}^{E}=\frac{X_{t}^{U}}{X_{t}^{E}}
$$

which implies,

$$
x_{t}^{U}=\frac{1}{2} .
$$

In this extreme case, when growth slows down in $E$ there is no change in the exchange rate at impact, and a gradual increase in $q$ at rate $\left(g-g^{E}\right)$ thereafter. Since the output share is constant, the instantaneous return in terms of $X^{U}$ is also constant and equal to

$$
r=\frac{1}{2} g+\frac{1}{2}\left(g^{E}+\frac{\dot{q}^{E}}{q^{E}}\right)+\delta \theta=g+\delta \theta .
$$

One can also check that

$$
V_{t}^{i}=W_{t}^{i}=\frac{q^{i} X_{t}^{i}}{\theta}
$$

Hence neither country needs to run current account imbalances in response to the collapse in $g^{E}$. The reason is that the terms of trade offset perfectly the relative decline in output growth, leaving relative wealth and relative output unchanged (when measured in the same units). Log preferences eliminate the model's dynamics! ${ }^{19}$

Consider now the more realistic case where $\sigma>1$. From the previous discussion, we infer that $q^{E}$ increases at a smaller rate than the growth differential. For instance, with $\sigma=4-$ not an unreasonable value ${ }^{20}$ - and a growth differential of 1 percent per year, the model implies that $U$ 's terms of trade would worsen at 0.25 percent per year. This implies an even slower real exchange rate depreciation, which eventually converges to a steady state value of $((1-\gamma) / \gamma)^{1 /(1-\sigma)}$.

We can prove a result similar to Proposition 1 and the associated Metzler diagram in presence of exchange rates. From $r_{t}=\dot{X}_{t} / X_{t}+\delta \theta$, we have

$$
r_{t}=g x_{t}^{U}+\left(g^{E}+\dot{q}_{t} / q_{t}\right)\left(1-x_{t}^{U}\right)+\delta \theta .
$$

Since $x_{t}^{U}$ tends to 1 , we obtain:

$$
\lim _{t \rightarrow \infty} r_{t}=g+\delta \theta=r_{a u t}^{U}
$$

From

$$
\begin{aligned}
\dot{W}_{t}^{E} & =\left(r_{t}-\theta\right) W_{t}^{E}+(1-\delta) q_{t}^{E} X_{t}^{E} \\
r_{t} V_{t}^{E} & =\delta q_{t} X_{t}^{E}+\dot{V}_{t}^{E}
\end{aligned}
$$

${ }^{19}$ This well-known result was first shown by Cole and Obstfeld (1991).

${ }^{20}$ See later in this section for a discussion of the calibration of $\sigma$. 
it is apparent that

$$
\begin{aligned}
& \frac{W_{t}^{E}}{q_{t}^{E} X_{t}^{E}} \underset{t \rightarrow \infty}{\rightarrow} \frac{(1-\delta)}{\theta+\left(g^{E}+\frac{1}{\sigma}\left(g-g^{E}\right)\right)-r_{a u t}^{U}} \\
& \frac{V_{t}^{E}}{q_{t}^{E} X_{t}^{E}} \underset{t \rightarrow \infty}{\rightarrow} \frac{\delta}{r_{a u t}^{U}-\left(g^{E}+\frac{1}{\sigma}\left(g-g^{E}\right)\right)}
\end{aligned}
$$

Thus, the asymptotic wealth and asset values are similar to those of Proposition 1, the only difference being that $g^{E}$ has to be replaced by $g^{E}+\frac{1}{\sigma}\left(g-g^{E}\right)<g^{U}$.

By a reasoning analogous to that in Lemma 1, we obtain:

$$
\frac{C A_{t}^{U}}{q_{t}^{E} X_{t}^{E}}=-\frac{C A_{t}^{E}}{q_{t}^{E} X_{t}^{E}} \underset{t \rightarrow \infty}{\rightarrow}\left(g^{E}+\frac{1}{\sigma}\left(g-g^{E}\right)\right)\left[\frac{\delta}{r_{a u t}^{U}-\left(g^{E}+\frac{1}{\sigma}\left(g-g^{E}\right)\right)}-\frac{(1-\delta)}{\theta+\left(g^{E}+\frac{1}{\sigma}\left(g-g^{E}\right)\right)-r_{a u t}^{U}}\right] \leq 0
$$

As we discussed above, when $\sigma=1$ there is no current account deficit. At the other extreme, when $\sigma$ tends to infinity we recover the deficits from Proposition 1 since there is no offsetting long-run exchange rate movement. While there can be non-monotonicities in the intermediate region, the general message is apparent: The possibility of long-run exchange rate movements attenuates rather than exacerbates the wealth effects associated with differential growth and hence attenuates asymptotic current account deficits. The main reason behind the latter is that the reduced wealth effects at impact when $\sigma<\infty$ leads to smaller initial trade deficits in $U$ and hence smaller accumulated net external liabilities.

Figure 8 presents a simulation of a decline in $g^{E}$ in the two-goods model when $\sigma=4$ and $\gamma=0.9 .{ }^{21}$ It confirms our conclusions from the one-good model -see Figure 3.

Comparing panels A-D in both figures, we observe that relative price movements limit the size of the current account deficit (Panel A, 8.2 percent versus 17 percent in the single good model) and limit accordingly the build-up in net foreign debt (Panel B, -57 percent after 24 years versus -75 percent of output after 15 years in the single good model). Accordingly, the increase in the share of $U$ in global portfolios is more muted (Panel D). Panel C reports the world's real instantaneous rates of return, defined as the output-weighted average of both countries real returns. The trajectory of the world real interest rates is very similar to the one obtained in panel $\mathrm{C}$ in figure 3: from 6 percent, the world interest rate drops to 5.41 percent on impact, then climbs very slowly back toward 6 percent. Finally, Panel E reports the real exchange rate $\lambda=P^{E} / P^{U}$. On impact $\lambda$ appreciates by about 7.8 percent, then gradually but persistently depreciates. Importantly, in our model it is the latter effect that dominates (dampens) wealth effects and hence limits the initial current account deficits in $U$.

\footnotetext{
${ }^{21}$ Feenstra (1994) finds a value of 4 for $\sigma$ while Broda and Weinstein (2004) report estimates ranging from 17 at 7 -digit between 1972-1988 to 4 for 3-digit goods in 1990-2001. Obstfeld and Rogoff (2004) use an elasticity of 2 while Obstfeld and Rogoff (2000) used a value of 6 . Obstfeld and Rogoff (2004) use a weight on domestic tradeable of 0.7. But they also assume a share of expenditure on non-tradeable equal to 0.75 . This corresponds to a share of domestic consumption on domestic goods $\gamma$ of 0.925 , not far from our 0.9 .
} 
Panel A: Current Account/Output

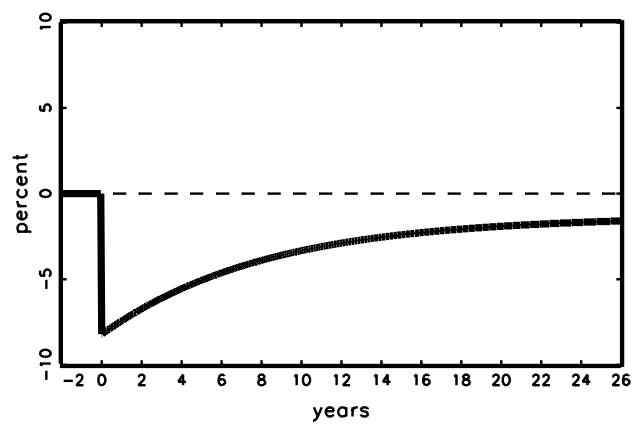

Panel C: World Real Interest Rate

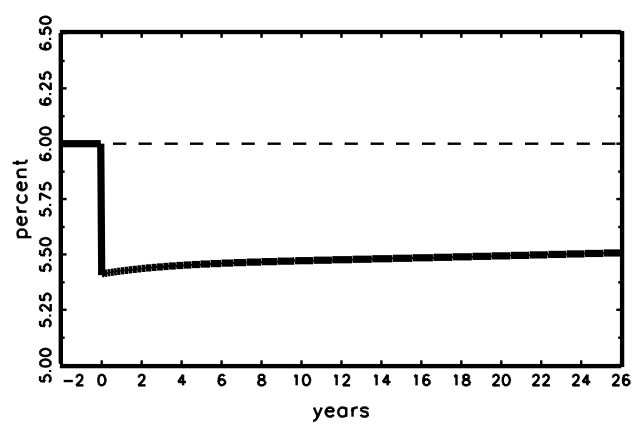

Panel E: Real Exchange Rate

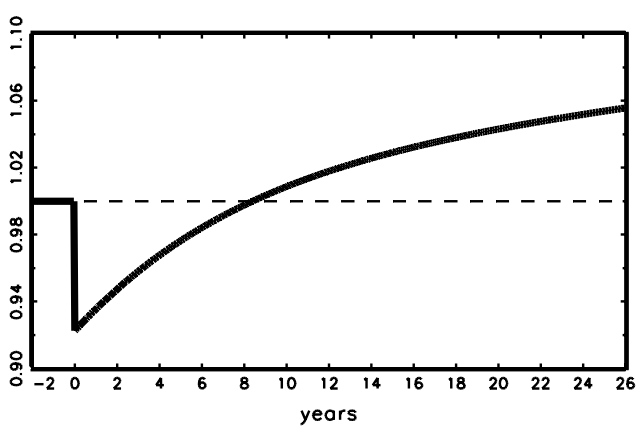

Panel B: Net Foreign Assets/Output

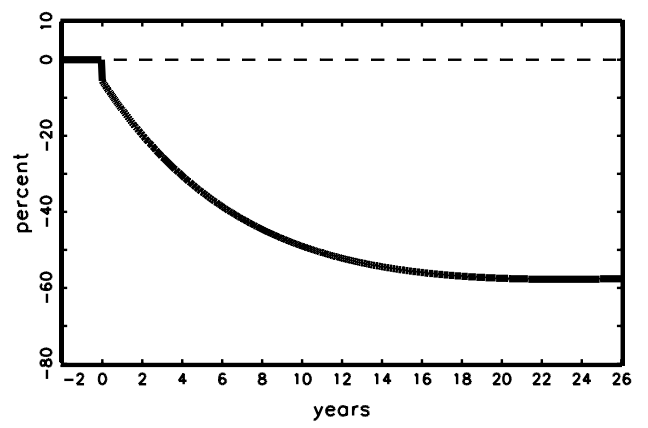

Panel D: Global Portfolio Share

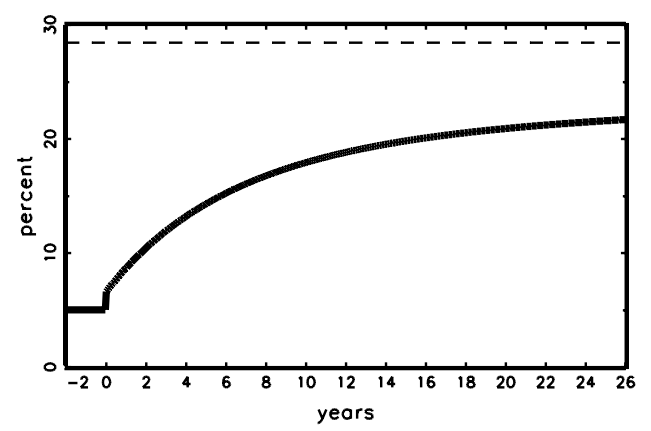

Figure 8: A Collapse in $g^{E}$ in the two-good model

Finally, Figure 9 presents the case of an unexpected reversal in $g^{E}$ back to $g$ after ten years. The increase in $g^{E}$ is now associated with a sharp reversal of the current account deficit in $U$ and a depreciation of its currency at $t=10$, but followed by a gradual appreciation so that by year $25, U$ 's exchange rate is at 1.02 rather than the 1.06 in Figure 8. The purpose of this figure is to highlight that in our setup there can be a sharp reversal in the current account and exchange rate, but this would stem from a fundamental shock, and not from the exogenous and spontaneous correction of an "anomaly," as the conventional view would have it. 
Panel A: Current Account/Output

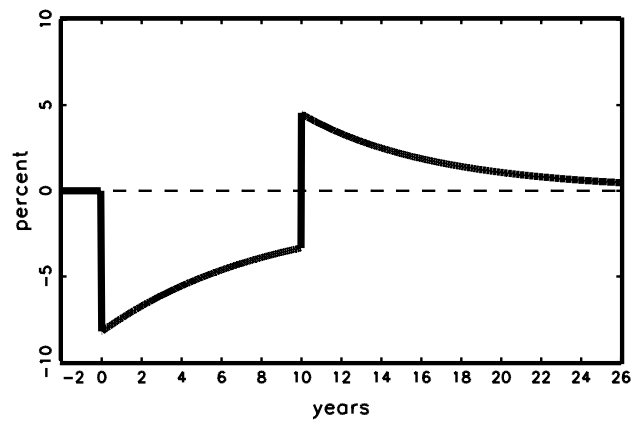

Panel C: World Real Interest Rate

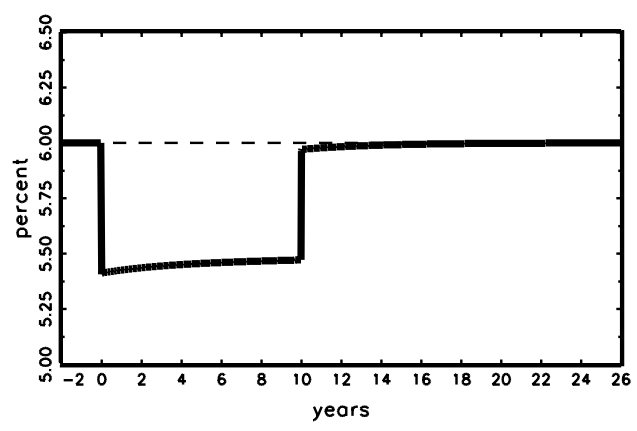

Panel E: Real Exchange Rate

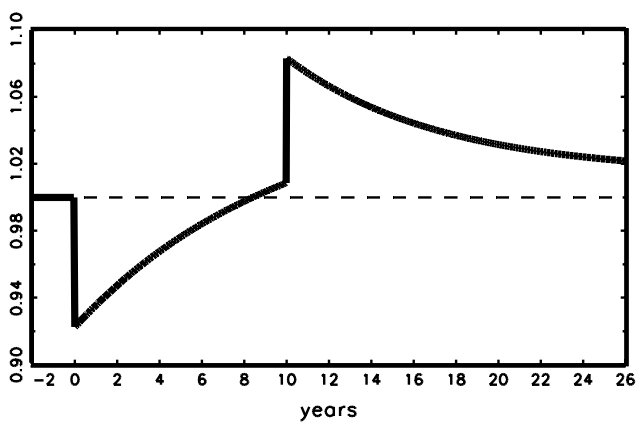

Panel B: Net Foreign Assets/Output

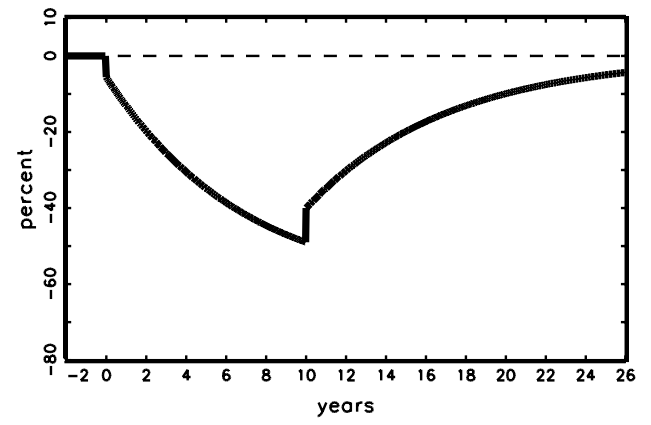

Panel D: Global Portfolio Share

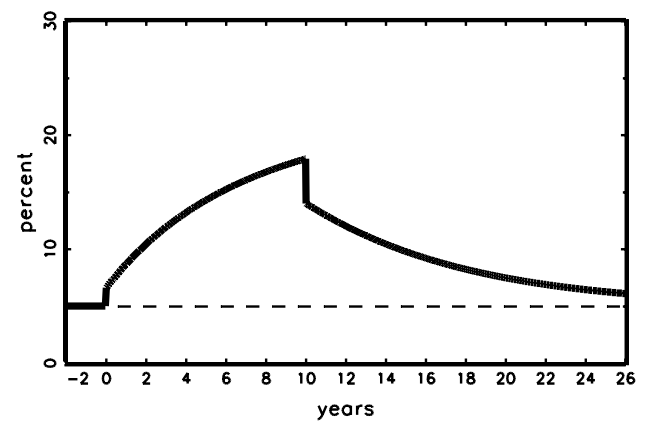

Figure 9: A Collapse in $g^{E}$ in the two-good model, followed by a reversal at $t=10$ 


\subsection{A $U-R$ World}

Consider now the interaction between $U$ and $R$. As before, let's consider a scenario where R's ability to capitalize financial assets drops from $\delta$ to $\delta^{R}<\delta$ while $g^{R}=g$.

Following the same steps as before, we obtain:

$$
V_{t}=W_{t}=\frac{X_{t}}{\theta}
$$

where $X_{t}=X_{t}^{U}+q_{t}^{R} X_{t}^{R}, V_{t}=V_{t}^{U}+V_{t}^{R}$ and $W_{t}=W_{t}^{U}+W_{t}^{R}$. The instantaneous rate of return now satisfies:

$$
r_{t}=r_{\text {aut }}^{U}+\left(1-x_{t}^{U}\right)\left(\frac{\dot{q}_{t}^{R}}{q_{t}^{R}}-\theta\left(\delta-\delta^{R}\right)\right)
$$

which is similar to equation (16), except for the rate of change of the terms of trade.

Since output growth is the same in both countries, a reasoning similar to the previous section implies that $\dot{q}_{t}^{R} / q_{t}^{R}=0$ asymptotically. The absence of relative supply effect implies that the long run terms of trade are stable. On impact, however, the relative demand effect is still present: the decline in $\delta^{R}$ reduces the value of $R$ 's financial assets which, under portfolio home bias, reduces $R$ 's financial wealth. Finally, due to consumption home bias, the decline in financial wealth in $R$ reduces disproportionately the relative demand for $R$ 's good and induces a decline in $q^{R}$.

Asymptotically, substituting $\dot{q}_{t}^{R} / q_{t}^{R}=0$ into the expression for $r_{t}$, we see that the interest rate reaches the value:

$$
\lim _{t \rightarrow \infty} r_{t}=r_{\infty}^{+}=r_{\text {aut }}^{U}-\left(1-x_{\infty}^{U}\right)\left(\delta-\delta^{R}\right) \theta<r_{\text {aut }}^{U}
$$

where $x_{\infty}^{U}$ represents the asymptotic share of $U$ 's output. Now Lemma 1 applies, so that

$$
\begin{array}{cl}
\frac{V_{t}^{R}}{q_{t}^{R} X_{t}^{R}} \underset{t \rightarrow \infty}{\rightarrow} \frac{\delta^{R}}{r_{\infty}^{+}-g} ; & \frac{V_{t}^{U}}{X_{t}^{U}} \underset{t \rightarrow \infty}{\rightarrow} \frac{\delta}{r_{\infty}^{+}-g}, \\
\frac{W_{t}^{R}}{q_{t}^{R} X_{t}^{R}} \underset{t \rightarrow \infty}{\rightarrow} \frac{1-\delta^{R}}{\theta+g-r_{\infty}^{+}} ; & \frac{W_{t}^{U}}{X_{t}^{U}} \underset{t \rightarrow \infty}{\rightarrow} \frac{1-\delta}{\theta+g-r_{\infty}^{+}}
\end{array}
$$

and the asymptotic current account satisfies

$$
\frac{C A_{t}^{U}}{X_{t}^{U}} \underset{t \rightarrow \infty}{\rightarrow} g\left(\frac{1-\delta}{\theta+g-r_{\infty}^{+}}-\frac{\delta}{r_{\infty}^{+}-g}\right)<0
$$

Since $r_{\text {aut }}^{U}>r_{\infty}^{+}, U$ runs a permanent current account deficit.

The results of Proposition 2 carry through with one exception: the asymptotic output share $x_{\infty}^{U}$ may differ from the initial output share $x_{0}^{U}$. It is immediate that the current account deficit will be larger if $r_{\infty}^{+}<r^{+}$, or, from the formula for $r_{\infty}^{+}$, if

$$
x_{\infty}^{U}<x_{0}^{U}
$$


Since $x_{t}^{U}=X_{0}^{U} /\left(q_{t}^{R} X_{0}^{R}+X_{0}^{U}\right)$, this is equivalent to $q_{\infty}^{R}>q_{0}^{R}$ or $\lambda_{\infty}>\lambda_{0}$. If the real exchange rate depreciates asymptotically, which it does in our simulations, the asymptotic current account worsens, compared to the single good case.

The conventional rebalancing channel has implications for exchange rate movements but does not affect the core story for capital flows, which lies somewhere else in global asset markets. ${ }^{22}$ In fact, although small for our calibrated parameters, adding the exchange rate dimension allows $U$ to run larger asymptotic current account deficits and hold larger net foreign liabilities. The reason is that the long run depreciation reduces $U$ 's share of output $\left(x_{\infty}^{U}\right)$. This is equivalent to a further reduction in the global supply of assets and pushes world interest rates lower (Panel C), reducing $U$ 's borrowing costs.

Figure 10 presents the results of a simulation similar to Figure 5. Panel E demonstrates that the real exchange rate appreciates on impact by 17 percent, then depreciates slowly, returning to $\lambda_{0^{-}}$in 12 years, then depreciating by another 3.5 percent. Given the previous discussion, the long run depreciation of the real exchange rate implies that the asymptotic current account deficits are (slightly) larger than in the single good model (-2.96 percent versus -2.85 percent in the single good model) with a correspondingly higher permanent accumulation of net foreign liabilities (99\% of output versus 95\%). Panel $\mathrm{C}$ shows that our conclusion with respect to the decline in interest rates from the single good model remains largely unchanged.

Finally, Figure 11 documents the paths when $\delta^{R}$ returns unexpectedly to $\delta$ at $t=10$. Comparing Figures 10 and 11, we observe that when $\delta^{R}$ jumps, $U$ 's current account deficit turns around and its real exchange rate depreciates, and then appreciates slowly. The latter comes with a rapid de-cumulation of claims on $U$ by $R$ residents (panel $\mathrm{D}$ ). Again, the point of this figure is that for these sharp reversals to take place, there must be a reversal of the causes that triggered the initial shift, since the strength of automatic rebalancing forces is tenuous at best.

\subsection{The Three Regions World}

For completeness, we conclude this section by integrating the three regions. The results are as expected, with the additional insight that since a crash in $\delta^{R}$ has a disproportionate effect on $V^{U}$ relative to $V^{E}$ when $g^{E}<g$, and, given financial home bias, on $W^{U}$, at impact $U$ 's currency appreciates not only vis-a-vis $R$ 's currency but also vis-a-vis E's currency (due to consumption-home-bias). However, this effect is small relative to the depreciation of $R$ exchange vis-a-vis both $U$ and $E$.

Figure 12 reports the bilateral real exchange rates between $U, E$ and $R$. We start the economy in a symmetric equilibrium $\left(g^{i}=g\right.$ and $\left.\delta^{i}=\delta\right)$, with $x_{0}^{U}=x_{0}^{E}=0.425$ and $x_{0}^{R}=0.15 .{ }^{23}$ We then reduce $E$ 's

\footnotetext{
${ }^{22}$ The rebalancing channel refers to the mechanism whereby the rapid accumulation of claims on $U$ by $R$ residents, together with the consumption home bias assumption requires a future a depreciation of the real exchange rate.

${ }^{23} \mathrm{We}$ also assume that the home good preferences are such that $\gamma_{i i}=0.9, \gamma_{i j}=0.05$ for $i \neq j$.
} 
Panel A: Current Account/Output

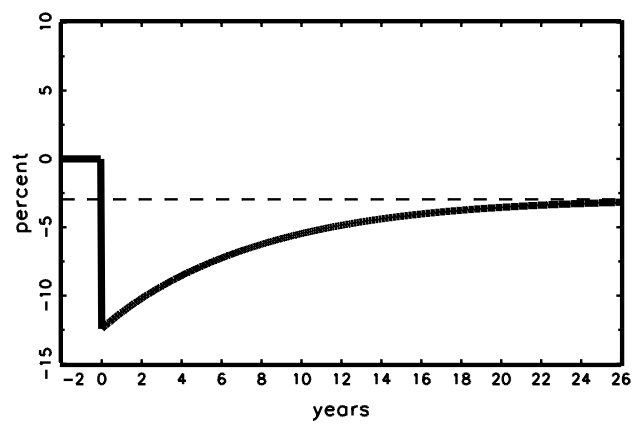

Panel C: World Real Interest Rate

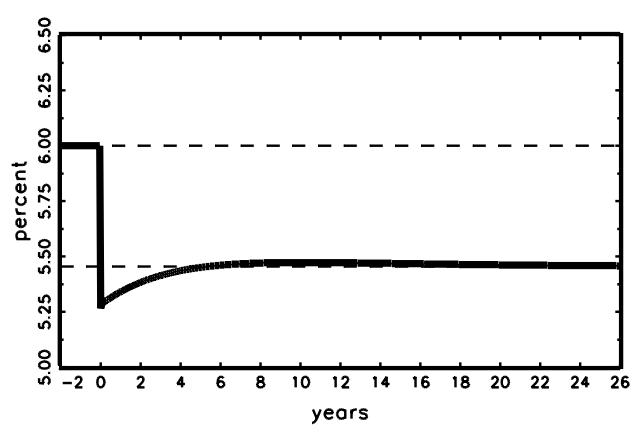

Panel E: Real Exchange Rate

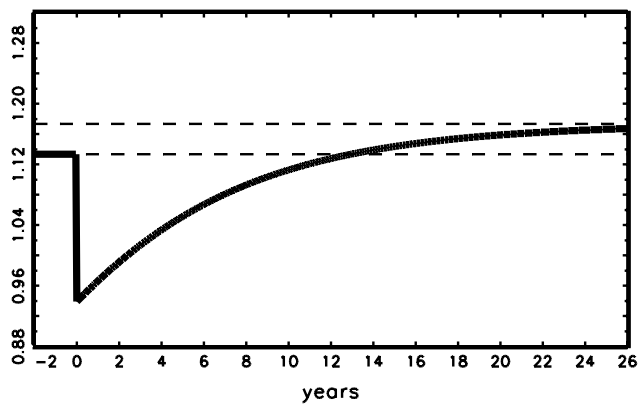

Panel B: Net Foreign Assets/Output

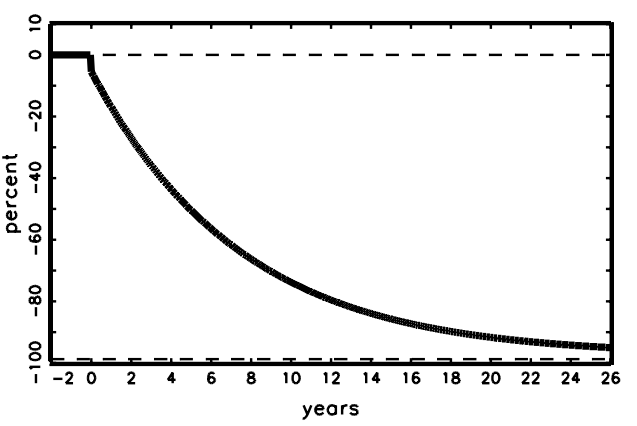

Panel D: Global Portfolio Share

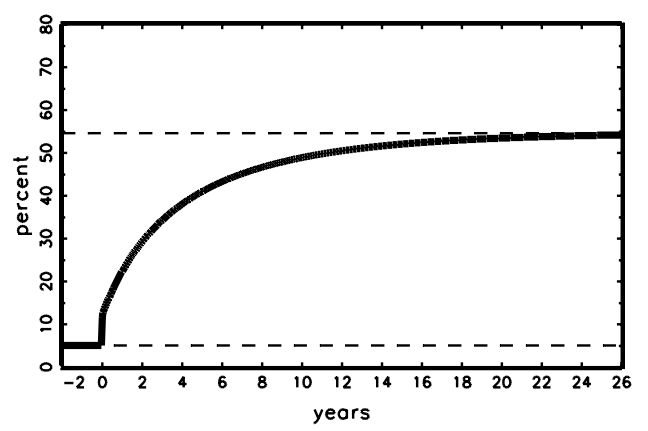

Figure 10: A Collapse in $\delta^{R}$ in the two-good model

growth at $t=0$. This leads to an immediate appreciation of $U^{\prime} s$ real exchange rate, as in section 4.2. Then, at $t=5$, we decrease $\delta^{R}$ so that $V^{R}$ decreases by $50 \%$. The figure confirms our intuition: the crash in $\delta^{R}$ increases $V^{U} / V^{E}$, which increases the relative demand for good $U$ and appreciates $U^{\prime} s$ real exchange rate relative to $E$ by $2 \%$.

\section{$5 \quad$ Final Remarks}

In this paper we have proposed a framework to analyze the effects of different structural shocks on global capital flows, portfolio shares and interest rates. The framework highlights the connection between a region's 
Panel A: Current Account/Output

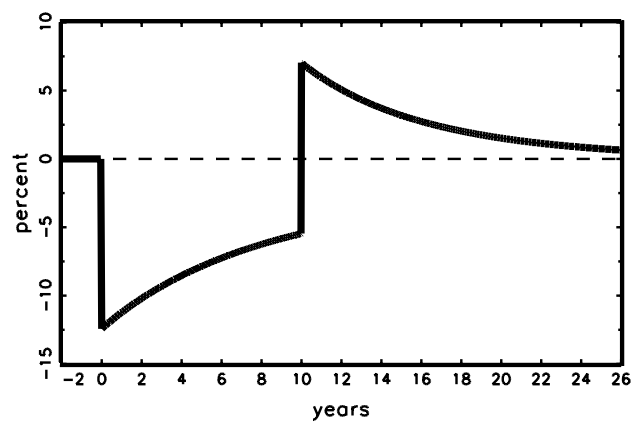

Panel C: World Real Interest Rate

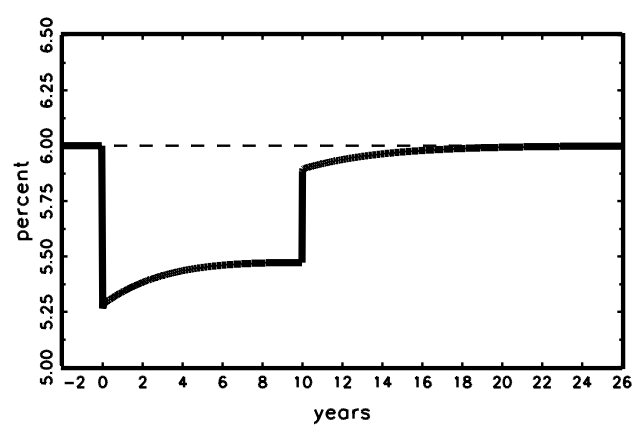

Panel E: Real Exchange Rate

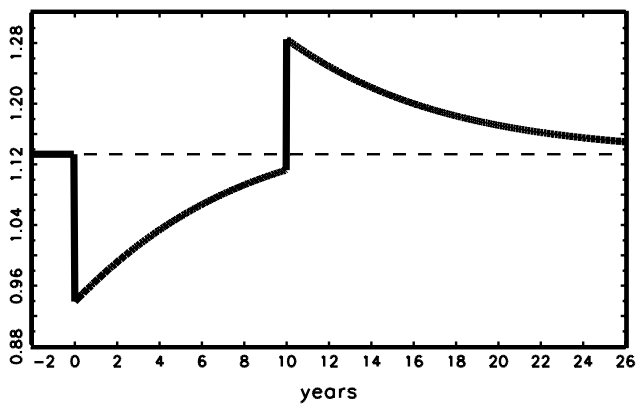

Panel B: Net Foreign Assets/Output

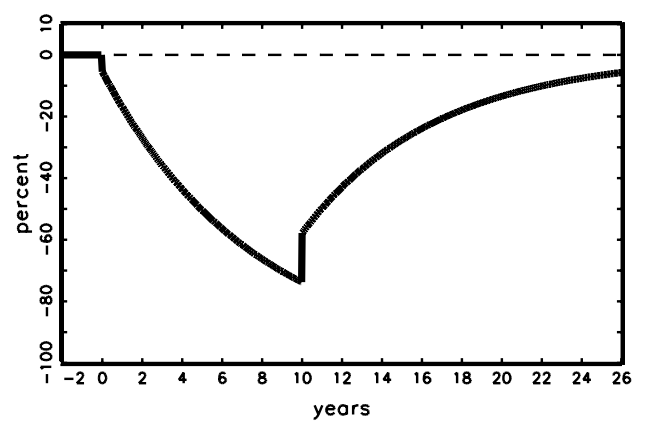

Panel D: Global Portfolio Share

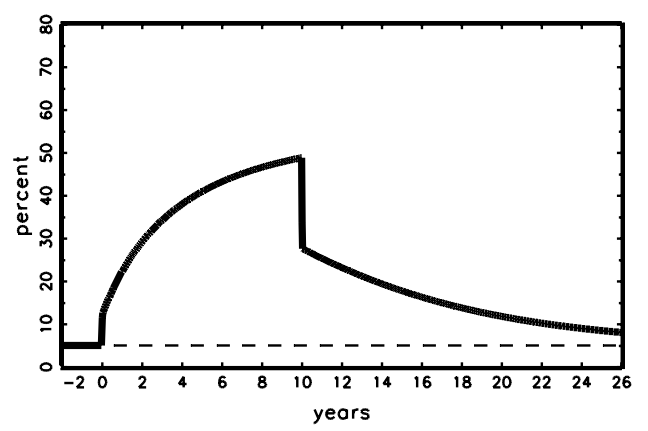

Figure 11: A Collapse in $\delta^{R}$ in the two-good model, followed by a reversal at $t=10$

relative fundamentals - in particular, its growth potential and the quality (or acceptance) of its financial assets - and its ability to produce financial assets for global savers.

We used the framework to discuss two shocks that we view as particularly relevant in explaining recent "global imbalances" and the "interest rate conundrum." The first one is a sustained growth slowdown in $E$; The second one is a collapse in the capacity to generate assets in $R$. The former captures well the effect of a relative slowdown in the Euro area and Japan. The second captures aspects of the Japanese bubble crash in the early 1990s and the developments in much of emerging markets and newly industrialized economies of Asia in the aftermath of the Asian and Russian crises at the end of the 1990s. We also explored the global effects of the interaction between $R$ 's limited financial markets and its fast potential growth. All these effects 


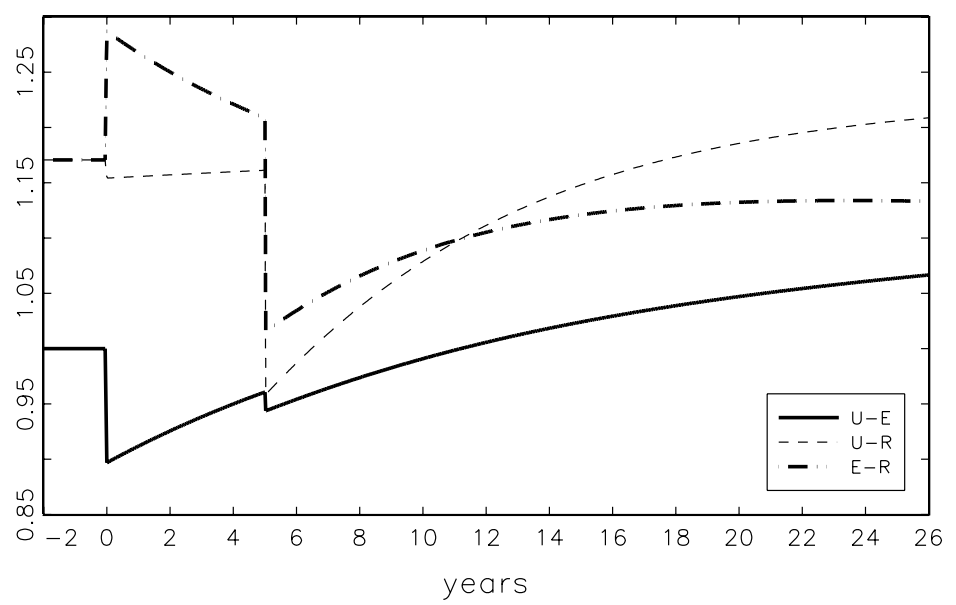

Figure 12: Bilateral Real Exchange Rates in the U-E-R model. Collapse in $g^{E}$ at $t=0$ followed by a collapse in $\delta^{R}$ at $t=5$

point in the same direction: To a sustained reallocation of savings toward $U$ and to lower interest rates.

The framework is flexible enough to explore a variety of experiments and issues that have been postulated in the "global imbalances" debate. For example, a dimension we did not develop in the main text but is trivial to analyze is that of an increase in a regions' saving propensity (for example, a decline in $\theta^{R}$ ). The implications would be similar in terms of the path of capital flows, measured saving rates, interest rates and the interaction with fast growth in $R$, as those following a crash in $\delta^{R}$. However the implications would be entirely different for $V^{R}$ : While a drop in $\delta^{R}$ comes with an initial crash in $R$ 's asset prices, an increase in the propensity to save does the opposite. This distinction is important since the dramatic acceleration in capital flows toward the US in the late 1990s from $R$ came with a crash rather a rise in asset values in $R$. This is not to say that a drop in $\theta^{R}$ is not part of the story, as it is a convenient short-cut to represent the more recent increase in saving rates by commodity producing economies (which have come with high local asset prices) or even to capture demographic factors. Moreover, such drop further strengthens the downward pressure on long rates when combined with fast growth in $R$. However, in terms of timing it is the crash in $\delta^{R}$ that most likely started the massive flows from $R$ to $U$.

Note also that in the model of Section 3, a crash in $\delta^{R}$ naturally leads to a domestic investment slump in $R$, as the return on projects not implemented by $U$ or $E$ falls. This is yet another implication that goes well with the facts, as the investment slump story is one that is used often to explain low real interest rates and capital flows to $U$.

One could also model some of the aspects of fiscal deficits in the US as an increase in $\theta^{U}$. This would indeed lead to current account deficits in $U$ but it would increase rather than reduce interest rates, and 
hence it is probably not the main factor behind current "global imbalances."

Similarly, one could model the process of globalization as one in which regions are gradually allowed to participate in global capital markets. In that case, one could generate a downward trend in global interest rates as low $\delta^{R}$ economies are integrated. This probably accounts for some of the downward pressure observed on rates since the 1990s.

Finally, a word of caution. Our framework also highlights that the current configuration of global asymmetries is likely to continue building the already large net external liabilities of $U$. Leverage always comes with risks. We have already illustrated within our framework how a reversal in the relative growth advantage of $U$ vis-a-vis $E$, or in $R$ 's financial underdevelopment (perhaps the most likely reversal channel), would lead to a sharp reversal in capital flows, interest rates and exchange rates. One could also go outside the model and add a credit-risk concern with $U$ 's liabilities and generate a more harmful reversal. Our model has little to say about the latter possibility, although it seems remote. Moreover, one of our main points has been that such risk does not follow as an unavoidable outcome of the current scenario, as the latter is consistent with current global asymmetries in growth potential and financial development. 


\section{References}

Bernanke, Ben, "The Global Saving Glut and the U.S. Current Account Deficit," Sandridge Lecture, Virginia Association of Economics, Richmond, Virginia, Federal Reserve Board March 2005.

Blanchard, Olivier, Francesco Giavazzi, and Filipa Sa, "International Investors, the U.S. Current Account, and the Dollar," in "Brookings Papers on Economic Activity" Spring 2005.

Broda, Christian and David E. Weinstein, "Globalization and the Gains from Variety," NBER Working Paper 10314, National Bureau of Economic Research, February 2004.

Caballero, Ricardo J. and Arvind Krishnamurthy, "Bubbles and Capital Flow Volatility: Causes and Risk Management," Journal of Monetary Economics, January 2006, 53:1.

, Emmanuel Farhi, and Mohammad L. Hammour, "Speculative Growth: Hints from the U.S. Economy," American Economic Review, forthcoming 2006.

Cole, Harold and Maurice Obstfeld, "Commodity Trade and International Risk Sharing: How Much Do Financial Markets Matter?," Journal of Monetary Economics, 1991, 28, 3-24.

Despres, Emile, Charles Kindleberger, and Walter Salant, "The Dollar and World Liquidity: A Minority View," The Economist, February 5 1966, 218 (5).

Dooley, Michael and Peter Garber, "Is It 1958 or 1968? Three Notes on the Longevity of the Revived Bretton Woods System," in Richard Clarida, ed., G-7 Current Account Imbalances: Sustainability and Adjustment, forthcoming 2006.

Dooley, Michael P., David Folkerts-Landau, and Peter Garber, "An Essay on the Revived Bretton Woods System," NBER Working Paper 9971, National Bureau of Economic Research September 2003.

Feenstra, Robert C, "New Product Varieties and the Measurement of International Prices," American Economic Review, 1994, 84 (1), 157-77.

Fischer, Stanley, "The Asian Crisis: A View from the IMF," Address at the Midwinter Conference of the Bankers' Association for Foreign Trade, Washington, D.C. January 1998.

Gourinchas, Pierre-Olivier and Hélène Rey, "From World Banker to World Venture Capitalist: US External Adjustment and the Exorbitant Privilege," in Richard Clarida, ed., G-7 Current Account Imbalances: Sustainability and Adjustment, forthcoming 2006.

IMF, World Economic Outlook, Washington DC: IMF, 2005. 
Kindleberger, Charles, "Balance of Payments Deficits and the International Market for Liquidity," Essays in International Finance, May 1965, 46.

Kouri, Pentti, "Balance of Payment and the Foreign Exchange Market: A Dynamic Partial Equilibrium Model," in Jagdeep Bhandari and Bluford Putnam, eds., Economic Interdependance and Flexible Exchange Rates, MIT Press, 1982, pp. 116-156.

Kraay, Aart and Jaume Ventura, "The Dot-Com Bubble, the Bush Deficits, and the U.S. Current Account," in Richard Clarida, ed., G-7 Current Account Imbalances: Sustainability and Adjustment, forthcoming 2006 .

Lane, Philip R. and Gian Maria Milesi-Ferretti, "A Global Perspective on External Positions," in Richard Clarida, ed., G-7 Current Account Imbalances: Sustainability and Adjustment, forthcoming 2006.

Obstfeld, Maurice and Kenneth Rogoff, "The Six Major Puzzles in International Macroeconomics: Is There a Common Cause?," in Ben Bernanke and Kenneth Rogoff, eds., N.B.E.R. Macroeconomics Annual, MIT Press Cambridge MA 2000, pp. 73-103.

__ and __ , "The Unsustainable US Current Account Position Revisited," NBER Working Paper 10869, National Bureau of Economic Research, November 2004.

and __ , "Global Current Account Imbalances and Exchange Rate Adjustments," in "Brookings Papers on Economic Activity" Spring 2005. 


\section{A Appendix}

\section{A.1 Proof of Lemma 1}

We have

$$
\begin{aligned}
V_{t} & =\int_{t}^{\infty} \delta X_{s} e^{-\int_{t}^{s} r_{u} d u} d s=\delta X_{t} \int_{t}^{\infty} e^{-\int_{t}^{s}\left(r_{u}-g\right) d u} d s \\
W_{t} & =W_{0} e^{\int_{0}^{t}\left(r_{s}-\theta\right) d s}+\int_{0}^{t}(1-\delta) X_{s} e^{\int_{s}^{t}\left(r_{u}-\theta\right) d u} d s \\
& =(1-\delta) X_{t}\left[\frac{W_{0}}{(1-\delta) X_{t}} e^{\int_{0}^{t}\left(r_{s}-\theta\right) d s}+\int_{0}^{t} e^{\int_{s}^{t}\left(r_{u}-\theta-g\right) d u} d s\right]
\end{aligned}
$$

The Lemma follows from the fact that

$$
\begin{aligned}
\lim _{t \rightarrow \infty} \int_{t}^{\infty} e^{-\int_{t}^{s}\left(r_{u}-g\right) d u} d s & =\frac{1}{r-g} \\
\lim _{t \rightarrow \infty} \int_{0}^{t} e^{\int_{s}^{t}\left(r_{u}-\theta-g\right) d u} d s & =\frac{1}{g+\theta-r}
\end{aligned}
$$

and

$$
\lim _{t \rightarrow \infty} \frac{W_{0}}{(1-\delta) X_{t}} e^{\int_{0}^{t}\left(r_{s}-\theta\right) d s}=0
$$

when $g<r<g+\theta$.

\section{A.2 Proof of Lemma 3}

By definition, we can write:

$$
W_{t}^{j}=\alpha_{t}^{j, i} V_{t}^{i}+\left(1-\alpha_{t}^{i, j}\right) V_{t}^{j}
$$

and the net asset demand as:

$$
W_{t}^{j}-V_{t}^{j}=\alpha_{t}^{j, i} V_{t}^{i}-\alpha_{t}^{i, j} V_{t}^{j}
$$

so that:

$$
\begin{aligned}
C A_{t}^{i} & =\dot{W}_{t}^{i}-\dot{V}_{t}^{i} \\
& =(1-\delta) X_{t}^{i}-\theta W_{t}^{i}+r_{t} W_{t}^{i}-\dot{V}_{t}^{i} \\
& =(1-\delta) X_{t}^{i}-\theta W_{t}^{i}+r_{t}\left(W_{t}^{i}-V_{t}^{i}\right)+\delta X_{t}^{i} \\
& =X_{t}^{i}-\theta W_{t}^{i}+r_{t}\left(\alpha_{t}^{i, j} V_{t}^{j}-\alpha_{t}^{j, i} V_{t}^{i}\right)
\end{aligned}
$$

\section{A.3 The role of assumption 4}

Suppose that assumption 4 does not hold. This appendix shows that the essence of our analysis is not affected by this change, although the expressions are less friendly, if we are willing to make the minimal assumption that $g^{E}>0$, so that $g>(1-\delta) \theta$ if Assumption 4 does not hold. 
Let $x_{t}^{u} \equiv X_{t}^{U} / X_{t}$ be the relative size of country U's endowment. Since $X_{0}^{U}=X_{0}^{E}$, we have

$$
x_{t}^{u}=\frac{X_{0}^{U} e^{g t}}{X_{0}^{U} e^{g t}+X_{0}^{E} e^{g^{E} t}}=\frac{1}{1+e^{-\left(g-g^{E}\right) t}}
$$

It will prove useful to compute $\int_{0}^{t} x_{s}^{u} d s$ in closed form

$$
\begin{aligned}
\int_{0}^{t} x_{s}^{u} d s & =\int_{0}^{t} \frac{1}{1+e^{-\left(g-g^{E}\right) x}} d x=\frac{1}{g-g^{E}} \int_{e^{-\left(g-g^{E}\right) t}}^{1} \frac{1}{u(1+u)} d u \\
& =\frac{1}{g-g^{E}}\left[\ln \left(\frac{u}{1+u}\right)\right]_{e^{-\left(g-g^{E}\right) t}}^{1}=\frac{1}{g-g^{E}} \ln \left(\frac{1+e^{\left(g-g^{E}\right) t}}{2}\right)
\end{aligned}
$$

Note that we can express $r_{t}=\frac{\dot{X}_{t}}{X_{t}}+\delta \theta$ as

$$
r_{t}=\delta \theta+g^{E}+x_{t}^{U}\left(g-g^{E}\right)
$$

Solving forward the differential equation for $V_{t}^{E}$, we get

$$
\begin{aligned}
V_{t}^{E} & =\int_{t}^{\infty} \delta X_{s}^{E} e^{-\int_{t}^{s} r_{u} d u} d s \\
& =\int_{t}^{\infty} e^{-\delta \theta(s-t)-g^{E}(s-t)-\left(g-g^{E}\right) \int_{t}^{s} x_{h}^{u} d h} \delta X_{t}^{E} e^{g^{E}(s-t)} d s \\
& =\delta X_{t}^{E} \int_{t}^{\infty} e^{-\delta \theta(s-t)-\left(g-g^{E}\right) \int_{t}^{s} x_{h}^{u} d h} d s \\
& =\delta X_{t}^{E} \int_{t}^{\infty} \frac{1+e^{-\left(g-g^{E}\right) t}}{1+e^{-\left(g-g^{E}\right) s}} e^{-\left(g-g^{E}+\delta \theta\right)(s-t)} d s
\end{aligned}
$$

Similarly, we can solve forward the differential equation for $V_{t}^{U}$

$$
\begin{aligned}
V_{t}^{U} & =\int_{t}^{\infty} \delta X_{s}^{U} e^{-\int_{t}^{s} r_{u} d u} d s \\
& =\int_{t}^{\infty} e^{-\delta \theta(s-t)-g^{E}(s-t)-\left(g-g^{E}\right) \int_{t}^{s} x_{h}^{u} d h} \delta X_{t}^{U} e^{g(s-t)} d s \\
& =\delta X_{t}^{U} \int_{t}^{\infty} e^{-\delta \theta(s-t)+\left(g-g^{E}\right)(s-t)-\left(g-g^{E}\right) \int_{t}^{s} x_{h}^{u} d h} d s \\
& =\delta X_{t}^{U} \int_{t}^{\infty} \frac{1+e^{-\left(g-g^{E}\right) t}}{1+e^{-\left(g-g^{E}\right) s}} e^{-\delta \theta(s-t)} d s
\end{aligned}
$$

We can also solve the differential equation for $W_{t}^{E}$ and $W_{t}^{U}$, with initial conditions $W_{0^{+}}^{E}$ and $W_{0^{+}}^{U}$ 


$$
\begin{aligned}
W_{t}^{E}= & W_{0^{+}}^{E} e^{\int_{0}^{t}\left(r_{s}-\theta\right) d s}+\int_{0}^{t}(1-\delta) X_{s}^{E} e^{f_{s}^{t}\left(r_{u}-\theta\right) d u} \\
= & W_{0^{+}}^{E} \exp \left[-(1-\delta) \theta t+g^{E} t+\left(g-g^{E}\right) \int_{0}^{t} x_{s}^{u} d s\right] \\
& +(1-\delta) X_{t}^{E} \int_{0}^{t} \exp \left[-(1-\delta) \theta(t-s)+\left(g-g^{E}\right) \int_{s}^{t} x_{h}^{u} d h\right] d s \\
= & W_{0^{+}}^{E} \frac{e^{g^{E} t}+e^{g t}}{2} e^{-(1-\delta) \theta t}+(1-\delta) X_{t}^{E} \int_{0}^{t} \frac{1+e^{-\left(g-g^{E}\right) t}}{1+e^{-\left(g-g^{E}\right) s} e^{\left(g-g^{E}-(1-\delta) \theta\right)(t-s)} d s} \\
W_{t}^{U}= & W_{0^{+}}^{U} e^{\int_{0}^{t}\left(r_{s}-\theta\right) d s}+\int_{0}^{t}(1-\delta) X_{s}^{U} e^{f_{s}^{t}\left(r_{u}-\theta\right) d u} \\
= & W_{0^{+}}^{U} \exp \left[-(1-\delta) \theta t+g^{E} t+\left(g-g^{E}\right) \int_{0}^{t} x_{s}^{u} d s\right] \\
& +(1-\delta) X_{t}^{U} \int_{0}^{t} \exp \left[-(1-\delta) \theta(t-s)-\left(g-g^{E}\right)(t-s)+\left(g-g^{E}\right) \int_{s}^{t} x_{h}^{u} d h\right] d s \\
= & W_{0^{+}}^{U} \frac{e^{g^{E} t}+e^{g t}}{2} e^{-(1-\delta) \theta t}+(1-\delta) X_{t}^{U} \int_{0}^{t} \frac{1+e^{-\left(g-g^{E}\right) t}}{1+e^{-\left(g-g^{E}\right) s}} e^{-(1-\delta) \theta(t-s)} d s
\end{aligned}
$$

Hence

$$
\begin{aligned}
V_{t}^{E}= & \delta X_{t}^{E} \int_{t}^{\infty} \frac{1+e^{-\left(g-g^{E}\right) t}}{1+e^{-\left(g-g^{E}\right) s}} e^{-\left(g-g^{E}+\delta \theta\right)(s-t)} d s \\
& \underset{t \rightarrow \infty}{\sim} \frac{\delta X_{t}^{E}}{g-g^{E}+\delta \theta} \\
W_{t}^{E}= & W_{0^{+}}^{E} \frac{e^{g^{E} t}+e^{g t}}{2} e^{-(1-\delta) \theta t}+(1-\delta) X_{t}^{E} \int_{0}^{t} \frac{1+e^{-\left(g-g^{E}\right) t}}{1+e^{-\left(g-g^{E}\right) s} e^{\left(g-g^{E}-(1-\delta) \theta\right)(t-s)} d s} \\
& \underset{t \rightarrow \infty}{\sim} W_{0^{+}}^{E} \frac{e^{(g-(1-\delta) \theta) t}}{2}+(1-\delta) X_{0}^{E} e^{(g-(1-\delta) \theta) t} \int_{0}^{t} \frac{1+e^{-\left(g-g^{E}\right) t}}{1+e^{-\left(g-g^{E}\right) s}} e^{-\left(g-g^{E}-(1-\delta) \theta\right) s} d s \\
& \underset{t \rightarrow \infty}{\sim} W_{0^{+}}^{E} \frac{e^{(g-(1-\delta) \theta) t}}{2}+(1-\delta) X_{0}^{E} e^{(g-(1-\delta) \theta) t} \int_{0}^{\infty} \frac{1}{1+e^{-\left(g-g^{E}\right) s}} e^{-\left(g-g^{E}-(1-\delta) \theta\right) s} d s
\end{aligned}
$$

Therefore, it is easy to see that

$$
\begin{aligned}
& V_{t}^{E} \underset{t \rightarrow \infty}{\sim} \frac{\delta X_{t}^{E}}{g-g^{E}+\delta \theta} \\
& \dot{V}_{t}^{E} \underset{t \rightarrow \infty}{\sim} \frac{\delta g^{E} X_{t}^{E}}{g-g^{E}+\delta \theta} \\
& W_{t}^{E} \underset{t \rightarrow \infty}{\sim} e^{(g-(1-\delta) \theta) t}\left(W_{0^{+}}^{E}+(1-\delta) X_{0}^{E}\right)\left(\frac{1}{2}+\int_{0}^{\infty} \frac{1}{1+e^{-\left(g-g^{E}\right) s}} e^{-\left(g-g^{E}-(1-\delta) \theta\right) s} d s\right) \\
& \dot{W}_{t}^{E} \underset{t \rightarrow \infty}{\sim}(g-(1-\delta) \theta) e^{(g-(1-\delta) \theta) t}\left(W_{0^{+}}^{E}+(1-\delta) X_{0}^{E}\right)\left(\frac{1}{2}+\int_{0}^{\infty} \frac{1}{1+e^{-\left(g-g^{E}\right) s}} e^{-\left(g-g^{E}-(1-\delta) \theta\right) s} d s\right)
\end{aligned}
$$


Hence

$$
\begin{aligned}
& C A_{t}^{U} \underset{t \rightarrow \infty}{\sim}-\dot{W}_{t}^{E} \\
& C A_{t}^{U} \underset{t \rightarrow \infty}{\sim}-(g-(1-\delta) \theta) e^{(g-(1-\delta) \theta) t}\left(W_{0^{+}}^{E}+(1-\delta) X_{0}^{E}\right)\left(\frac{1}{2}+\int_{0}^{\infty} \frac{1}{1+e^{-\left(g-g^{E}\right) s}} e^{-\left(g-g^{E}-(1-\delta) \theta\right) s} d s\right)
\end{aligned}
$$

Now the decomposition is:

$$
\begin{aligned}
& \theta W_{t}^{E}-X_{t}^{E} \underset{t \rightarrow \infty}{\sim} \theta W_{t}^{E} \\
& r_{t}\left(V_{t}^{E}-W_{t}^{E}\right) \underset{t \rightarrow \infty}{\sim}-(g+\delta \theta) W_{t}^{E}
\end{aligned}
$$

Therefore, the trade balance is positive while income flows are negative (and larger in absolute value than the trade balance), as in the main text.

\section{A.4 Proof of proposition 3}

The first inequality of the first statement follows directly from $\left(\delta-\delta^{R}\right)>0$, as in Proposition 2 . The second inequality follows from the fact that $x_{t}^{U}$ declines over time. Asymptotically, $r_{t}$ converges to $r_{a u t}^{R}$.

From Lemma 1, we know that

$$
\begin{aligned}
\frac{C A_{t}^{U}}{X_{t}^{U}} & \rightarrow \quad-g \frac{r_{a u t}^{U}-r_{a u t}^{R}}{\left(g+\theta-r_{a u t}^{R}\right)\left(r_{a u t}^{R}-g\right)}<0 \\
& \rightarrow \infty \\
& g^{R}>g
\end{aligned}
$$

On the other hand, from Proposition 2 we have that

$$
\begin{aligned}
\frac{C A_{t}^{U}}{X_{t}^{U}} & \rightarrow-g \frac{r_{\text {aut }}^{U}-r^{+}}{\left(g+\theta-r^{+}\right)\left(r^{+}-g\right)}<0 \\
& \rightarrow \rightarrow \infty \\
g^{R} & =g
\end{aligned}
$$

where $r^{+}=r_{a u t}^{U}-\theta\left(1-x_{0}^{U}\right)\left(\delta-\delta^{R}\right)$ (see (18)). From assumption $5, r^{+}>r_{a u t}^{R}$ and the second statement in the proposition now follows since

$$
\frac{r-r_{a u t}^{U}}{(g+\theta-r)(r-g)}=\frac{1-\delta}{g+\theta-r}-\frac{\delta}{r-g}
$$

is increasing with respect to $r$.

\section{A.5 The $U-E-R$ model}

In this case the equations describing the dynamics of each country's wealth are 


$$
\begin{aligned}
& \dot{W}_{t}^{U}=-\theta W_{t}^{U}+(1-\delta) X_{t}^{U}+r_{t} W_{t}^{U} \\
& \dot{W}_{t}^{E}=-\theta W_{t}^{E}+(1-\delta) X_{t}^{E}+r_{t} W_{t}^{E} \\
& \dot{W}_{t}^{R}=-\theta W^{R}+\left(1-\delta^{R}\right) X_{t}^{R}+r_{t} W_{t}^{R}
\end{aligned}
$$

which aggregate to the following differential equation for global wealth

$$
\dot{W}_{t}=\left(1-\delta+\left(\delta-\delta^{R}\right) x_{t}^{R}\right) X_{t}+\left(r_{t}-\theta\right) W_{t}
$$

Similarly, the asset pricing equations for each country's tree are

$$
\begin{aligned}
& r_{t} V_{t}^{U}=\delta X_{t}^{U}+\dot{V}_{t}^{U} \\
& r_{t} V_{t}^{E}=\delta X_{t}^{E}+\dot{V}_{t}^{E} \\
& r_{t} V_{t}^{R}=\delta^{R} X_{t}^{R}+\dot{V}_{t}^{R}
\end{aligned}
$$

which imply the following equation for the total value of world assets

$$
r_{t} V_{t}=\left(\delta-\left(\delta-\delta^{R}\right) x_{t}^{R}\right) X_{t}+\dot{V}_{t}
$$

As usual, investment equals savings in the world market:

$$
W_{t}=V_{t}
$$

which implies a goods market clearing condition

$$
W_{t}=\frac{X_{t}}{\theta}
$$

The equilibrium interest rate can be solved for

$$
\begin{aligned}
r_{t} & =\frac{\dot{X}_{t}}{X_{t}}+\theta\left(\delta\left(1-x_{t}^{R}\right)+\delta^{R} x_{t}^{R}\right) \\
& =x_{t}^{U} g^{U}+x_{t}^{E} g^{E}+x_{t}^{R} g^{R}+\theta\left(\delta\left(1-x_{t}^{R}\right)+\delta^{R} x_{t}^{R}\right) \\
& =x_{t}^{U}\left(g^{U}+\delta \theta\right)+x_{t}^{E}\left(g^{E}+\delta \theta\right)+x_{t}^{R}\left(g^{R}+\delta^{R} \theta\right)
\end{aligned}
$$

Hence the world interest rate is a average of $g^{U}+\delta \theta, g^{E}+\delta \theta$ and $g^{R}+\delta^{R} \theta$ with weights given by the relative size of the endowment of each country. 


\section{A.6 Proof of proposition 4}

Define $r_{\infty}$ the asymptotic interest rate. $r_{a u t}^{R} \leq r_{\infty}<r_{\text {aut }}^{U}$ with equality when $g^{R}>g$. Note that:

$$
\begin{aligned}
& W_{t}^{E} \underset{t \rightarrow \infty}{\sim} \frac{(1-\delta) X_{t}^{E}}{g^{E}+\theta-r_{\infty}} \\
& W_{t}^{U} \underset{t \rightarrow \infty}{\sim} \frac{(1-\delta) X_{t}^{U}}{g+\theta-r_{\infty}} \\
& W_{t}^{R} \underset{t \rightarrow \infty}{\sim} \frac{\left(1-\delta^{R}\right) X_{t}^{R}}{g^{R}+\theta-r_{\infty}}
\end{aligned}
$$

and

$$
\begin{aligned}
& V_{t}^{E} \underset{t \rightarrow \infty}{\sim} \frac{\delta X_{t}^{E}}{r_{\infty}-g^{E}} \\
& V_{t}^{U} \underset{t \rightarrow \infty}{\sim} \frac{\delta X_{t}^{U}}{r_{\infty}-g} \\
& V_{t}^{R} \underset{t \rightarrow \infty}{\sim} \frac{\delta^{R} X_{t}^{R}}{r_{\infty}-g^{R}}
\end{aligned}
$$

Hence

$$
\begin{aligned}
\frac{\delta^{R}}{V_{t}^{E}} \frac{\partial V_{t}^{E}}{\partial \delta^{R}} & =\frac{\delta^{R}}{r_{\infty}-g^{E}} \cdot \frac{\partial r_{\infty}}{\partial \delta^{R}} \\
\frac{\delta^{R}}{V_{t}^{U}} \frac{\partial V_{t}^{U}}{\partial \delta^{R}} & =\frac{\delta^{R}}{r_{\infty}-g} \cdot \frac{\partial r_{\infty}}{\partial \delta^{R}}
\end{aligned}
$$

which implies

$$
\frac{\frac{\delta^{R}}{V_{t}^{U}} \frac{\partial V_{t}^{U}}{\partial \delta^{R}}}{\frac{\delta^{R}}{V_{t}^{E}} \frac{\partial V_{t}^{E}}{\partial \delta^{R}}}=\frac{r_{\infty}-g^{E}}{r_{\infty}-g}=1+\frac{g-g^{E}}{r_{\infty}-g}
$$

That is, the long run proportional increase in the value of assets following a collapse in $\delta^{R}$ is larger in $U$ than in $E$. The results on the current account follow immediately from its definition and the fact that asymptotic wealths are less sensitive than initial wealth to interest rate changes.

\section{A.7 Investment and gross flows}

We need to distinguish between the old trees (with $\delta^{R}$ ) and the new trees. Define $v_{t}^{R o}$ the value of an old $\mathrm{R}$ tree, $v_{t}^{R n}$ the value of a new $\mathrm{R}$ tree and $v_{t}^{U}$ the value of a $\mathrm{U}$ tree. We have

$$
\begin{aligned}
r_{t} v_{t}^{R o} & =\delta^{R} Z_{t}^{R}+\dot{v}_{t}^{R o} \\
r_{t} v_{t}^{R n} & =\delta Z_{t}^{R}+\dot{v}_{t}^{R n} \\
r_{t} v_{t}^{U} & =\delta Z_{t}^{U}+\dot{v}_{t}^{U}
\end{aligned}
$$

The aggregate value of $U$ trees is $V_{t}^{U}=N_{t}^{U} v_{t}^{U}$ and satisfies

$$
r_{t} V_{t}^{U}=\delta X_{t}^{U}+\dot{V}_{t}^{U}-g^{n} V_{t}^{U}
$$


The aggregate value of new trees in $R$ is $V_{t}^{R n}=\left(N_{t}^{R}-N_{0}^{R}\right) v_{t}^{R n}$ and satisfies

$$
\begin{aligned}
r_{t} V_{t}^{R n} & =\delta\left(N_{t}^{R}-N_{0}^{R}\right) Z_{t}^{R}+\left(N_{t}^{R}-N_{0}^{R}\right) \dot{v}_{t}^{R n} \\
& =\delta X_{t}^{R n}+\dot{V}_{t}^{R n}-g^{n} N_{t}^{R} v_{t}^{R n}
\end{aligned}
$$

Finally, define the aggregate value of the old trees in $R$ as $V_{t}^{R o}=N_{0}^{R} v_{t}^{R o}$. It satisfies:

$$
r_{t} V_{t}^{R o}=\delta^{R} X_{t}^{R o}+\dot{V}_{t}^{R o}
$$

Aggregate wealth then evolves according to

$$
r_{t} V_{t}=\delta\left(X_{t}^{U}+X_{t}^{R n}\right)+\delta^{R} X_{t}^{R o}+\dot{V}_{t}-g^{n} V_{t}^{U}-g^{n} N_{t}^{R} v_{t}^{R n}
$$

Let's now consider wealth accumulation equations:

$$
\begin{aligned}
& \dot{W}_{t}^{U}=\left(r_{t}-\theta\right) W_{t}^{U}+(1-\delta) X_{t}^{U}+g^{n} V_{t}^{U}+g^{n} N_{t}^{R} v_{t}^{R n}-P_{t}-I_{t} \\
& \dot{W}_{t}^{R}=\left(r_{t}-\theta\right) W_{t}^{R}+(1-\delta) X_{t}^{R n}+\left(1-\delta^{R}\right) X_{t}^{R o}+P_{t}
\end{aligned}
$$

Aggregating, we obtain:

$$
\dot{W}_{t}=\left(r_{t}-\theta\right) W_{t}+(1-\delta)\left(X_{t}^{U}+X_{t}^{R n}\right)+\left(1-\delta^{R}\right) X_{t}^{R o}+g^{n} V_{t}^{U}+g^{n} N_{t}^{R} v_{t}^{R n}-I_{t}
$$

Now equate $W=V$ and infer

$$
\theta W_{t}=X_{t}(1-\kappa)
$$

and the interest rate satisfies

$$
\begin{aligned}
r_{t} & =\frac{\dot{X}_{t}}{X_{t}}+\theta\left[\delta\left(x_{t}^{U}+x_{t}^{R n}\right)+\delta^{R} x_{t}^{R o}\right] /(1-\kappa)-\frac{\theta}{1-\kappa} g^{n} \frac{V_{t}^{U}+N_{t}^{R} v_{t}^{R n}}{X_{t}} \\
& =\frac{\dot{X}_{t}}{X_{t}}+\theta\left[\delta\left(x_{t}^{U}+x_{t}^{R n}\right)+\delta^{R} x_{t}^{R o}\right] /(1-\kappa)-\frac{\theta}{1-\kappa} g^{n} \frac{X_{t}(1-\kappa) / \theta+N_{0}^{R}\left[v_{t}^{R n}-v_{t}^{R o}\right]}{X_{t}} \\
& =\frac{\dot{X}_{t}}{X_{t}}-g^{n}+\theta\left[\delta\left(x_{t}^{U}+x_{t}^{R n}\right)+\delta^{R} x_{t}^{R o}\right] /(1-\kappa)-\frac{\theta}{1-\kappa} g^{n} \frac{N_{0}^{R}\left[v_{t}^{R n}-v_{t}^{R o}\right]}{X_{t}}
\end{aligned}
$$

As for aggregate output growth, we have

$$
\frac{\dot{X}_{t}}{X_{t}}=g^{n}+g^{z}
$$

so that:

$$
r_{t}=g^{z}+\theta\left[\delta\left(x_{t}^{U}+x_{t}^{R n}\right)+\delta^{R} x_{t}^{R o}\right] /(1-\kappa)-\frac{\theta}{1-\kappa} g^{n} \frac{N_{0}^{R}\left[v_{t}^{R n}-v_{t}^{R o}\right]}{X_{t}}
$$

The last term makes clear that the interest rate will initially be lower with FDI.

The reason is that $g^{n}\left(V^{U}+N_{t}^{R} v_{t}^{R n}\right)>g^{n} V_{t}$ so the asset demand in $U$ increases more when there is FDI. This depresses even more interest rates. 
Asymptotically, the last term disappears ( $\operatorname{since} v_{t}^{R n}$ and $v_{t}^{R o}$ grow at rate $g^{z}$ while $X$ grows at rate $g$ ) and $x_{t}^{R o}$ tends to 0 , so that

$$
r_{\infty}=g^{z}+\frac{\theta \delta}{1-\kappa}=r_{a u t}
$$

Since $v_{t}^{R n}>v_{t}^{R o}$ and $\delta^{R} x_{t}^{R o} \leq \delta x_{t}^{R o}$, we have:

$$
r_{t} \leq r_{\infty}
$$

The solution for the interest rate requires that we feed in a solution for the asset values $v_{t}^{R n}$ and $v_{t}^{R o}$. Integrating forward, they satisfy:

$$
\begin{aligned}
& v_{t}^{R o}=\delta^{R} Z_{t}^{R} \int_{t}^{\infty} e^{-\int_{t}^{s}\left(r_{u}-g^{z}\right) d u} d s \\
& v_{t}^{R n}=\delta Z_{t}^{R} \int_{t}^{\infty} e^{-\int_{t}^{s}\left(r_{u}-g^{z}\right) d u} d s
\end{aligned}
$$

so that $v_{t}^{R o} / v_{t}^{R n}=\delta^{R} / \delta$ and we obtain:

$$
r_{t}=g^{z}+\frac{\theta}{1-\kappa}\left[\delta\left(x_{t}^{U}+x_{t}^{R n}\right)+\delta^{R} x_{t}^{R o}\right]-\frac{\theta}{1-\kappa} g^{n} \frac{V_{t}^{R o}}{X_{t}^{R o}} x_{t}^{R o}\left(\delta / \delta^{R}-1\right)
$$

where

$$
\begin{aligned}
& V_{t}^{R o}=\delta^{R} X_{t}^{R o} \int_{t}^{\infty} e^{-\int_{t}^{s}\left(r_{u}-g^{z}\right) d u} d s \\
& \dot{V}_{t}^{R o}=-\delta^{R} X_{t}^{R o}+r_{t} V_{t}^{R o}
\end{aligned}
$$

What complicates the problem is that the equilibrium interest rate depends upon the current value of $V_{t}^{R o} / X_{t}^{R o}$ which in turn depends upon the entire sequence of future interest rates.

To solve this problem, define $\hat{v}_{t}^{R o}=V_{t}^{R o} / X_{t}^{R o}=v_{t}^{R o} / Z_{t}^{R}$. It satisfies

$$
\frac{d \hat{v}_{t}^{R o}}{d t}=\left(r_{t}-g^{z}\right) \hat{v}_{t}^{R o}-\delta^{R}
$$

and the interest rate can be expressed in terms of $\hat{v}_{t}^{R o}$ and $x_{t}^{R o}$ as:

$$
r_{t}=g^{z}+\frac{\theta}{1-\kappa}\left[\delta\left(1-x_{t}^{R o}\right)+\delta^{R} x_{t}^{R o}\right]-\frac{\theta}{1-\kappa} g^{n} \hat{v}_{t}^{R o} x_{t}^{R o}\left(\delta / \delta^{R}-1\right)
$$

If we note further that $x_{t}^{R o}$ follows simple dynamics:

$$
\dot{x}_{t}^{R o}=-g^{n} x_{t}^{R o}
$$

we obtain a single equation for $\frac{d \hat{v}_{t}^{R o}}{d t}$ with a forcing term $x_{t}^{R o}$ :

$$
\frac{d \hat{v}_{t}^{R o}}{d t}=\frac{\theta}{1-\kappa}\left[\delta\left(1-x_{t}^{R o}\right)+\delta^{R} x_{t}^{R o}-g^{n} \hat{v}_{t}^{R o} x_{t}^{R o}\left(\delta / \delta^{R}-1\right)\right] \hat{v}_{t}^{R o}-\delta^{R}
$$


We can solve this differential equation by 'reversing time'. Since $r_{t} \rightarrow r_{a u t}, \hat{v}_{t}^{\text {Ro }}$ settles to:

$$
\hat{v}_{\infty}^{R o}=\frac{\delta^{R}}{\delta} \frac{1}{\theta}
$$

So we can start at $\infty$ with $x^{R o}$ very close to 0 and $\hat{v}^{R o}=\hat{v}_{\infty}^{R o}$ then move 'back' in time until $x^{R o}=x_{0}^{R o}$.

Finally, after we find the solution, we can integrate backward the budget constraint to obtain wealth using $w_{t}^{U}=W_{t}^{U} / X_{t}^{U}$ and

$$
\begin{aligned}
\dot{w}_{t}^{U} & =\frac{\dot{W}_{t}^{U}}{X_{t}^{U}}-g w_{t}^{U} \\
& =\frac{\left(r_{t}-\theta\right) W_{t}^{U}+(1-\delta) X_{t}^{U}+g^{n} V_{t}^{U}+g^{n} N_{t}^{R} v_{t}^{R n}-P_{t}-I_{t}}{X_{t}^{U}}-g w_{t}^{U} \\
& =\left(r_{t}-\theta-g\right) w_{t}^{U}+\left(1-\delta-\frac{\kappa}{x_{t}^{U}}\right)+g^{n}\left(\hat{v}_{t}^{U}+\frac{N_{t}^{R} v_{t}^{R n}}{X_{t}^{R n}} \frac{x_{t}^{R n}}{x_{t}^{U}}-\kappa_{p} \frac{x_{t}^{R n}}{x_{t}^{U}}\right) \\
& =\left(r_{t}-\theta-g\right) w_{t}^{U}+\left(1-\delta-\frac{\kappa}{x_{t}^{U}}\right)+g^{n}\left(\frac{1-\kappa}{\theta} \frac{1}{x_{t}^{U}}-\hat{v}_{t}^{R o} \frac{x_{t}^{R o}}{x_{t}^{U}}\left(1-\frac{\delta}{\delta^{R}}\right)-\kappa_{p} \frac{x_{t}^{R n}}{x_{t}^{U}}\right)
\end{aligned}
$$

where the last line uses:

$$
V_{t}=\frac{1-\kappa}{\theta} \cdot X_{t}=V_{t}^{U}+N_{t}^{R} v_{t}^{R n}+N_{0}^{R} v_{t}^{R o}\left(1-\frac{\delta}{\delta^{R}}\right)
$$

\section{A.8 Solving the Model with Exchange Rates}

We use a shooting algorithm to solve for the initial terms of trade $q_{0+}^{i}$ and asset values $V_{0+}^{i}$ after the shock. Define $w_{t}=W_{t}^{U} / X_{t}^{U}$ and $x_{t}=X_{t}^{U} / \sum_{i} q_{t}^{i} X_{t}^{i}$. The system $\left(w_{t}, x_{t}, q_{t}^{i}\right)$ satisfies:

$$
\begin{aligned}
\dot{w}_{t} & =\left(r_{t}-\theta-g\right) w_{t}+(1-\delta) \\
1 & =\theta \gamma w_{t} P_{t}^{U(\sigma-1)}+(1-\gamma)\left(\frac{1}{x_{t}}-\theta w_{t}\right) P_{t}^{i(\sigma-1)} \\
\dot{x}_{t} & =x_{t}\left(1-x_{t}\right)\left(g-g^{i}-\frac{\dot{q}_{t}^{i}}{q_{t}^{i}}\right) \\
r_{t} & =x_{t}(g+\delta \theta)+\left(1-x_{t}\right)\left(g^{i}+\frac{\dot{q}_{t}^{i}}{q_{t}^{i}}+\delta^{i} \theta\right)
\end{aligned}
$$

Equation (37) is the wealth dynamics for country $i$. Equation (38) is the equilibrium condition on the market for good $U$. Equation (39)characterizes the law of motion of relative output. Unlike the one-good model, the path for future interest rates depends upon the future sequence of terms of trade, which depends upon the current and future asset values.

We start with a guess for the asset values $V_{0+}^{i}$ immediately after the shock. Given the initial portfolio allocation, we infer the initial wealth distribution $W_{0+}^{i}$. We then use (38) to solve for the initial terms of trade $q_{0+}$. Finally, we integrate (37)-(40) forward to construct the path of future interest rates and terms of 
trade $r_{t}, q_{t}$ consistent with equilibrium on the goods markets. We then use

$$
\begin{aligned}
V_{0+}^{i} & =\delta^{i} \int_{0}^{\infty} q_{t}^{i} X_{t}^{i} e^{-\int_{0}^{s} r_{u} d u} d s \\
& =q_{0}^{i} X_{0}^{i} \delta^{i} \int_{0}^{\infty} e^{-\theta \int_{0}^{s} \bar{\delta}_{u} d u} \frac{x_{s}^{i}}{x_{0}^{i}} d s
\end{aligned}
$$

to update our guess for $V_{0+}^{i}$, where $\bar{\delta}_{t}=\sum_{i} x_{t}^{i} \delta^{i}$ is the average (time-varying) capitalization ratio.

\section{A.9 "Calibration"}

This section discusses the choice of parameters underlying Figures 3-12. The 'calibration' of the model requires parameter values for $\delta, \theta, g, x_{0}, \alpha_{0}^{i U}, \alpha_{0}^{U i},\left(g-g^{E}\right)$ and $\left(\delta-\delta^{R}\right)$. We chose to assign parameters approximately based on US aggregate data. Table 1 summarizes our parameter assumptions.

\begin{tabular}{lcccccccccc} 
Parameter & $\theta$ & $g$ & $\delta$ & $x_{0}^{E}$ & $x_{0}^{R}$ & $\mu_{0-}^{i U}$ & $N A_{0-}^{U} / X_{0}^{U}$ & $\left.\frac{\Delta V^{R}}{V^{R}}\right|_{t=0}$ & $\left(g-g^{E}\right)$ & $\left(\delta-\delta^{R}\right)$ \\
\hline Value & 0.25 & $3 \%$ & 0.12 & 0.5 & 0.3 & 0.05 & 0 & -0.5 & $1.11 \%$ & 0.07
\end{tabular}

Table 1: Main Parameters

According to (4), we should think of $\theta$ as the output to financial wealth ratio, $X / W$. We obtain an estimate of $W$ as the net financial worth of the household sector. According to the US Flow of Funds, it is equal to $\$ 48.52$ trillion in $2004 .{ }^{24}$ With a US GDP of $\$ 11.73$ trillion in 2004 , this implies $\theta=\frac{11.73}{48.53} \sim 0.24$. In the simulations, we round this parameter to 0.25. Average output growth in the U.S. between 1950 and 2004 equals $3.33 \%$. We round this number and set the growth rate $g$ to 3 percent. Finally, we assume a value of $r_{a u t}$ equal to $6 \%$. This implies a value of $\delta$ of $(r-g) / \theta=0.12 .{ }^{25}$

We now turn to the output shares. We define $U$ as the U.S., the U.K. and Australia. These countries are good asset suppliers, and experienced robust growth in the past decade. We identify $E$ with developed nonoil producing countries with sound financial markets, but a lackluster growth performance. Accordingly, we define $E$ as countries from the European Union (less the UK), Iceland, Japan, New Zealand, and Switzerland. Finally, we identify $R$ with developing and oil producing countries with a good income growth potential, but limited asset production capacity. ${ }^{26}$

\footnotetext{
${ }^{24}$ See the Balance Sheet Table B100, line 42 of the September 2005 release.

${ }^{25}$ Another possible way to calibrate $\delta$ is to observe that in steady state, the $\mathrm{P} / \mathrm{E}$ ratio is $V / \delta X=1 / \delta \theta$. The $\mathrm{P} / \mathrm{E}$ ratio for the S\&P 500 averages 18.2 for the period 1950-2005.(see Robert Shiller's webpage at http://www.econ.yale.edu/ $\sim$ shiller/data.htm).) This yields $\delta=0.22$.. This value of $\delta$ would imply a risk free rate of $8 \%$ which we view as too high. Since not all assets in the economy are capitalizable, we prefer our estimate of $\delta$.

${ }^{26}$ The list includes Argentina, Brazil, Chile, China, Colombia, Costa Rica, Ecuador, Egypt, Hong-Kong, India, Indonesia, Korea, Mexico, Malaysia, Nigeria, Panama, Peru, Philippines, Poland, Russia, Singapore, Thailand and Venezuela. Output data for Poland and Russia starts in 1990.
} 
We measure the initial output share as the average output share between 1980 and $2003 .{ }^{27}$ We find

$$
\begin{aligned}
& x_{0}^{E}=\frac{X_{0}^{E}}{X_{0}^{E}+X_{0}^{U}} \approx 0.50 \\
& x_{0}^{R}=\frac{X_{0}^{R}}{X_{0}^{R}+X_{0}^{U}} \approx 0.30 .
\end{aligned}
$$

Lastly, we assume that the initial portfolio share for $U$-trees equals the share of US assets in ROW financial wealth, as estimated in figure 1(c). We adopt an initial value of 0.05 . Figure 1(c) is constructed as the ratio of US gross external liabilities (from the BEA's US International Investment Position) to the Rest of the World's financial wealth. To estimate the latter, we calculate the ratio of financial wealth to output for the US, the EU and Japan between 1982 and 2004. ${ }^{28}$ We find a GDP weighted average of 2.48. We apply this ratio to the Rest of the World GDP. For 2004, we estimate a financial wealth of $\$ 72$ trillion for the ROW and $\$ 36$ trillion for the US.

We set:

$$
\mu_{0-}^{i U}=\frac{\alpha_{0}^{i U} V_{0-}^{U}}{W_{0-}^{i}}=0.05
$$

where $i \in\{E, R\}$. Furthermore, we assume that the initial net foreign asset position is $0 .^{29}$ This implies that

$$
V_{0-}^{i}=W_{0-}^{i}=\frac{X_{0}^{i}}{\theta}
$$

Substituting into (41), we obtain

$$
\alpha_{0}^{i U}=\mu_{0-}^{i U} \frac{x_{0}^{i}}{1-x_{0}^{i}}
$$

which yields:

$$
\begin{aligned}
& \alpha_{0}^{E U}=0.05 \\
& \alpha_{0}^{R U}=0.02 .
\end{aligned}
$$

Finally, since

$$
W_{0-}^{U}-V_{0-}^{U}=\alpha_{0}^{U i} V_{0-}^{i}-\alpha_{0}^{i U} V_{0-}^{U}=0
$$

we find

$$
\alpha_{0}^{U i}=\mu_{0-}^{i U}=0.05
$$

We now describe the parameters for our shocks. We set the decline in E's growth rate, $\left(g-g^{R}\right)=1.11 \%$. According to the WDI, E's average growth rate between 1980 and 1992 was $2.73 \%$ and only $1.63 \%$ between 1992 and 2003 (ppp-adjusted).

\footnotetext{
${ }^{27}$ We use GDP data in current dollars from the World Development Indicators.

${ }^{28}$ Sources: US: Flow of Funds, Table B100 line 8, household financial assets; EU: Table 3.1 of the ECB Bulletin, financial and capital account of the non financial sector; Japan: Flow of Funds, households total financial assets, available at http://www.boj.or.jp/en/stat/stat_f.htm.

${ }^{29}$ According to the Bureau of Economic Analysis, the US had a zero net foreign asset position in 1988.
} 
We calibrate the decline in $\delta^{R}$ so that it matches the decline in asset values around the time of the Asian crisis. From Section 2.3, $R$ 's assets price drops from $V_{0-}^{R}=X_{0}^{R} / \theta$ before the shock to $V_{0+}^{R}=\delta^{R} / \theta \bar{\delta} X_{0}^{R}$ where $\bar{\delta}=\left(x_{0}^{U} \delta+\left(1-x_{0}^{U}\right) \delta^{R}\right)$ is the world capitalization index. Hence the drop in asset values at $t=0$ is

$$
\left.\frac{\Delta V^{R}}{V^{R}}\right|_{t=0}=\delta^{R} / \bar{\delta}-1<0 .
$$

Solving this expression for $\delta^{R}$, we obtain

$$
\left(\delta-\delta^{R}\right)=\delta\left(1+\frac{x_{0}^{U}\left[1+\left.\frac{\Delta V^{R}}{V^{R}}\right|_{t=0}\right]}{\left[\left.\frac{\Delta V^{R}}{V^{R}}\right|_{t=0}\left(1-x_{0}^{U}\right)-x_{0}^{U}\right]}\right) .
$$

The decline in dollar asset values was 37 percent in Hong-Kong, 75 percent in Korea and 83 percent in Indonesia. ${ }^{30}$ We conservatively consider a decline of 50 percent. This implies:

$$
\left(\delta-\delta^{R}\right)=0.07 ; \delta^{R}=0.05
$$

\footnotetext{
${ }^{30}$ We calculated the decline between July 1997 and January 1998 of the Hang Sen Composite Index (Hong Kong), the KOSPI (Korea) and the Jakarta Stock Index (Indonesia). All price indices were converted into dollars using daily exchange rates.
} 